\title{
Large scale in silico screening of materials for carbon capture through chemical looping
}

\author{
Cindy Y. Lau, ${ }^{\dagger}$ Matthew T. Dunstan, ${ }^{\ddagger}$ Wenting Hu, ${ }^{\dagger}$ Clare P. Grey, ${ }^{*, \ddagger}$ and \\ Stuart A. Scott*, \\ $\dagger$ Department of Engineering, University of Cambridge, Trumpington Street, Cambridge, \\ CB2 1PZ, United Kingdom \\ $\ddagger$ Department of Chemistry, University of Cambridge, Lensfield Road, Cambridge, CB2 \\ $1 E W$, United Kingdom \\ I Contributed equally to this work \\ E-mail: cpg27@cam.ac.uk; sas37@cam.ac.uk
}

\begin{abstract}
Chemical looping combustion (CLC) has been proposed as an efficient carbon capture process for power generation. Oxygen stored within a solid metal oxide is used to combust the fuel, either by releasing the oxygen into the gas phase, or by direct contact with the fuel; this oxyfuel combustion produces flue gases which are not diluted by $\mathrm{N}_{2}$. These materials can also be used to perform air-separation to produce a stream of oxygen mixed with $\mathrm{CO}_{2}$, which can subsequently be used in the conventional oxyfuel combustion process to produce sequesterable $\mathrm{CO}_{2}$.

The temperature and oxygen partial pressures under which various oxide materials will react in this way are controlled by their thermodynamic equilibria with respect to reduction and oxidation. While many materials have been proposed for use in chemical looping, many
\end{abstract}


suffer from poor kinetics or irreversible capacity loss due to carbonation, and therefore applying large scale in silico screening methods to this process is a promising way to obtain new candidate materials. In this study we report the first such large scale screening of oxide materials for oxyfuel combustion, utilising the Materials Project database of theoretically determined structures and ground state energies. From this screening several promising candidates were selected due to their predicted thermodynamic properties and subjected to initial experimental thermodynamic testing, with $\mathrm{SrFeO}_{3-\delta}$ emerging as a promising material for use in $\mathrm{CLC}$. $\mathrm{SrFeO}_{3-\delta}$ was further shown to have excellent cycling stability and resistance to carbonation over the temperatures of operation. This work further advances how in silico screening methods can be implemented as an efficient way to sample a large compositional space in order to find novel functional materials.

\section{Introduction}

In the past decade, a number of different potential technologies have been proposed to reduce the overall amount of greenhouse emissions released into the atmosphere. Some of these, such as producing electricity from renewable sources such as wind and solar energy, aim to address the challenge by reducing the amount of emissions directly. However, even with the most optimistic models, reducing emissions in this way will not be enough to achieve the agreed upon targets by 2050 and beyond. ${ }^{1}$ Therefore, carbon capture and sequestration (CCS) technologies have increasingly been recognised as necessary in order to more rapidly reduce the amount of $\mathrm{CO}_{2}$ being released in the atmosphere without the requirement that nations cease their current use of fossil fuels to produce energy.

One class of promising processes for carbon capture is based on chemical looping com-

bustion (CLC). ${ }^{2}$ Chemical looping makes use of cycles of oxidation and reduction of a solid oxygen carrier to transfer oxygen between air and a fuel. Several variants of chemical looping have been proposed for carbon capture, since its introduction in $1951 .^{3}$ In CLC, a fuel is 
brought into direct contact with a solid oxygen carrier where it is combusted in a gas-solid reaction. The reduced oxygen carrier can then be regenerated in a separate reactor using air, avoiding the presence of various unwanted gases such as $\mathrm{N}_{2}$ in the flue gases, making it much easier to purify and store $\mathrm{CO}_{2}$ subsequently. The resurgence in interest in CLC first arose in the 1980s as a way of avoiding the exergy penalty associated with combustion ${ }^{4,5}$ and later as a way of effecting carbon capture with a low energy penalty to help mitigate global warming. ${ }^{6,7}$ The reduction and oxidation cycles used in chemical looping operate at high temperatures, allowing waste heat to be recovered into the power cycle; in addition some of the exergy loss usually associated with direct combustion is used instead to drive the separation of oxygen from the air. This leads to an improvement in energy penalty compared with e.g. traditional oxyfuel combustion (in which $\mathrm{O}_{2}$ must be separated from the air cryogenically) or amine scrubbing (a low temperature, post combustion, absorption process). ${ }^{8}$ Within the past 15 years it has become particularly popular after its viability was demonstrated on a large scale and there were significant breakthroughs on new materials that could be used in the process. ${ }^{9,10}$

Typically oxygen carrier materials composed of transition metal oxides, e.g. oxides of copper, iron, nickel or manganese, ${ }^{11,12}$ in which the metal cation can be reduced to a lower oxidation state. More complex structures based on perovskites ${ }^{13,14}$ have also been proposed. One challenge is the production of particles which do not degrade in capacity over many cycles of oxidation and reduction. In practice this has meant supporting the active metal oxide with a diluent. ${ }^{15,16}$ Others have suggested that the cost of chemical looping will be more competitive if cheap natural minerals are used, e.g. the mineral ilmenite $\left(\mathrm{FeTiO}_{3}\right),{ }^{17}$ rather than more expensive manufactured materials.

Some solid carriers will spontaneously release gaseous $\mathrm{O}_{2}$ at high temperatures e.g. $\mathrm{CuO}^{18}$ or $\mathrm{CaMnO}_{3} \cdot{ }^{13,14}$ The equilibrium for

$$
4 \mathrm{CuO} \longrightarrow 2 \mathrm{Cu}_{2} \mathrm{O}+\mathrm{O}_{2}(\mathrm{~g})
$$


is such that at temperatures $>1173 \mathrm{~K}$ a substantial equilibrium $p_{\mathrm{O}_{2}}$ can be produced. Such materials, often referred to as CLOU materials (Chemical Looping with Oxygen Uncoupling), ${ }^{19}$ have been of particular interest when solid fuels are combusted, since the rate of combustion is limited by the rate at which the solid fuel can be converted to gaseous combustible species via gasification. ${ }^{20}$ The release of gas phase oxygen in the vicinity of the fuel rapidly accelerates the rate of solid combustion, and materials such as copper oxide can readily be regenerated in air at combustion temperatures.

The ability of metal oxides to release gas phase oxygen can also be exploited in a variant of oxyfuel combustion, in which the cryogenic air separation is replaced with a metal oxide cycle to produce the $\mathrm{O}_{2}$ (sometimes referred to as Chemical Looping Air Separation, or CLAS ${ }^{21}$ ). Whilst similar to CLOU, the materials for this process benefit from a higher equilibrium $p_{\mathrm{O}_{2}}$ at lower temperatures. The redox cycle in CLAS process requires heat input, hence materials such as copper oxide which require a very high temperature to produce a reasonable $p_{\mathrm{O}_{2}}$ are difficult to integrate into the power system, with supplementary heat often required at very high temperatures. ${ }^{22}$ On the other hand, materials which operate at too low a temperature would give a cycle which rejects heat that could not be easily recovered into the power cycle. The recovery of this waste heat is essential since the reduced energy penalty associated with CLAS (compared with oxyfuel with cryogenic air separation combustion) is solely due to the ability to integrate the rejected heat. A good compromise to optimise the power plant efficiency would be an air separation cycle that rejects heat at temperatures just above the top turbine inlet temperature in a typical power plant steam cycle, i.e. $\sim 823 \mathrm{~K}$. Of course, there may be valid reasons for operating hotter, despite the difficulties with heat integration, such as for non-stoichiometric materials high temperatures might increase their capacity, or in general higher temperatures might improve the apparent yields by increasing the rates of reaction. Increasing the yields of oxygen per cycle would reduce circulation rates in a continuous system, altering the energy required and also altering the size of equipment and CAPEX. 
This paper is concerned with finding materials suitable for chemical looping air separation. Besides having suitable redox thermodynamics, the ideal metal oxides have to possess good kinetic and cycling properties, as well as being suitable for potential scale-up to produce quantities sufficient to meet our current levels of $\mathrm{CO}_{2}$ production. A potential candidate based on thermodynamic criteria is $\mathrm{MnO}_{2} / \mathrm{Mn}_{2} \mathrm{O}_{3}$, which has an equilibrium temperature of $730 \mathrm{~K}$ in air. ${ }^{23}$ However, the reoxidation from $\mathrm{Mn}_{2} \mathrm{O}_{3}$ to $\mathrm{MnO}_{2}$ is extremely slow, ${ }^{24}$ rendering the material inappropriate as an oxygen carrier. Two other potential candidates that have equilibria near the temperature range of interest include $\mathrm{SrO}_{2} / \mathrm{SrO}$ and $\mathrm{BaO}_{2} / \mathrm{BaO}$, which have transitions around $625 \mathrm{~K}$ and $1150 \mathrm{~K}$, respectively. ${ }^{23}$ In fact, one of the first commercial processes for the production of oxygen, the Brin process, used beds of $\mathrm{BaO}$ to separate oxygen from air. ${ }^{25}$ Unfortunately it was found that $\mathrm{SrO}$ and $\mathrm{BaO}$ carbonate very easily even with the trace amount of $\mathrm{CO}_{2}$ in air, transforming to solid carbonates and significantly reducing their reversibility. Resistance to carbonation is therefore important, particularly for CLAS or oxyfuel combustion. In these processes, combustion cannot take place in pure $\mathrm{O}_{2}$ owing to the excess flame temperatures, instead a stream of $\mathrm{O}_{2}$, diluted with recycled flue gas, is used to combust the fuel. In a CLAS system, this can be achieved by bringing oxidised material into contact with the recycled flue gas (largely $\mathrm{CO}_{2}$ ). Thus, materials such as $\mathrm{BaO}$ or $\mathrm{SrO}$ used for air separation cannot be used. In fact, typical chemical looping materials, such as oxides of $\mathrm{Fe}, \mathrm{Cu}, \mathrm{Mn}$ or their mixtures with other refractory oxides do not carbonate at reaction temperatures. Any material containing oxides of $\mathrm{Ba}$ or $\mathrm{Sr}$ could carbonate, but its propensity for carbonation is likely to be reduced if part of a stable mixed oxide.

While there are a number of materials being considered for CLAS currently, including $\mathrm{CuO}$ and $\mathrm{Co}_{3} \mathrm{O}_{4}$, no single optimal material has been found to satisfy the many diverse criteria required, especially the requirement to be able to utilise waste heat. In such a situation, the discovery of novel materials with suitable properties is critical, as simply optimising existing materials will rarely lead to significant, order of magnitude changes. Additionally, with the advent of several large databases of theoretically calculated materials 
such as the Materials Project ${ }^{26}$ and the Open Quantum Materials Database, ${ }^{27}$ the ability to screen large swathes of potential materials for particular properties has rapidly improved. Indeed, this approach has already been successfully applied to other CCS areas, including high temperature carbonate looping ${ }^{28}$ and porous materials such as zeolites and metalorganic frameworks. ${ }^{29,30}$ Not only does this approach lead to the discovery of new promising candidate materials for the given application, but study of the screening results can lead to new insights as to the underlying parameters influencing their physical performance.

The current study aims to illustrate the overall pipeline for materials discovery in this field, starting with the application of large scale theoretical screening methods to discover promising candidate materials for chemical looping applications, followed by initial experimental testing of these candidates to determine their viability and finally more in-depth experimental characterisation of one material that the initial testing showed to have the best performance for CLAS. Whilst the focus here is on CLAS materials, the methodology outlined would be equally applicable to other chemical looping applications. In our work, we utilised the Materials Project database (www.materialsproject.com), which contains structural, electronic and energetic data for over 66000 compounds (as of June 2016) calculated using the Vienna Ab initio Simulation Package (VASP). ${ }^{26,31,32}$ Using both the REST Materials $\mathrm{API}^{33}$ and the Python package pymatgen ${ }^{34}$ which allows users to retrieve various entries from the database and screen for various features, we were able to predict the theoretical redox equilibria for thousands of compounds and simulate their performance for chemical looping in silico. Materials were primarily screened by their oxidation temperature in air in order to select materials that could be used most efficiently for chemical looping.

Promising candidate materials were subjected to a suite of experimental testing, including characterisation by x-ray diffraction, and thermogravimetry to determine a material's thermodynamic equilibrium, kinetics and redox cycling performance. The candidate materials were chosen because of both their suitable predicted redox thermodynamics, as well as their environmental and economic suitability in terms of chemical composition. The experi- 
mental studies not only showed that the theoretical screening was able to accurately predict the redox equilibria of solid state compounds, but also identified the perovskite strontium ferrite $\mathrm{SrFeO}_{3-\delta}$ as a novel solid state oxygen carrier that could be used in the intermediate temperature range and have excellent redox kinetics and stability over many redox cycles. Furthermore, its performance in the presence of $\mathrm{CO}_{2}$ was compared to an impure $\mathrm{SrFeO}_{3-\delta}$ sample, confirming its resistance to carbonation and showing that impurities are the source of unwanted carbonation reactions.

\section{Experimental}

\section{Materials Project screening methodology}

In a similar fashion to our previous work screening the Materials Project database for novel carbon capture and storage materials, ${ }^{28}$ we devised a screening methodology to firstly simulate oxidation and reduction reactions for the compounds within the database, and then to calculate $\Delta E_{D F T}$ for these reactions, being approximately equal to the Gibbs free energy at $0 \mathrm{~K}$. Following the previous work of Ong et al., ${ }^{35}$ in which open phase diagrams of the Li-Fe-P-O $\mathrm{O}_{2}$ system were constructed in order to determine the stability of various phases

under changing temperature and $p_{\mathrm{O}_{2}}$, we used the $\mathrm{O}_{2}$ chemical potential $\left(\mu_{\mathrm{O}_{2}}\right)$ to condense these parameters into a single variable.

In our screening we considered all binary and ternary compounds containing non-radioactive elements in order to present as thorough and extensive set of candidate reactions as possible, even though in reality many of these materials are either too expensive or hazardous for widespread use in chemical looping. The geometry optimised structures and ground state energies of the relevant materials were retrieved from the Materials Project database, having been previously calculated by the Materials Project using VASP. ${ }^{26}$

To obtain all compounds that were able to undergo a general oxidation reaction, ternary phase diagrams of the form $A-B-\mathrm{O}_{2}$ were simulated, where $A$ and $B$ are non-radioactive 
elements, using the Phase Diagram app within the pymatgen library. ${ }^{35,36}$ In order to analyse the reactivity of the phases studied with $\mathrm{O}_{2}$, we generated open phase diagrams with respect to $\mu_{\mathrm{O}_{2}}$, following the methodology of previous studies. ${ }^{35,37}$ The reader is encouraged to refer to these earlier publications for more details regarding open phase diagrams. Furthermore, we used the previously corrected Hubbard $U$ values optimised for oxidation energies of transition metal oxides which have been shown to lead to improved accuracy in cancelling the selfinteraction error arising from the use of the generalized gradient approximation (GGA) in the Materials Project DFT calculations. ${ }^{38}$

The initial results from the screening were filtered by restricting candidate compounds to those which were able to undergo redox reactions at $p_{\mathrm{O}_{2}}$ between $10^{2}-10^{6} \mathrm{~Pa}$ and between 150-1700 K. Although for actual use we are more interested in compounds that reduce in air $\left(p_{\mathrm{O}_{2}}=2.1 \times 10^{4} \mathrm{~Pa}\right)$ between $373-823 \mathrm{~K}$, we accepted materials within a wider tolerance in order to negate some of the inherent errors in the DFT calculated reaction energies, and not potentially exclude materials with desirable properties.

\section{Synthesis and characterisation methods}

$\mathrm{SrFeO}_{3}$ and $\mathrm{BaFeO}_{3}$ were synthesised using the citrate-nitrate method (modified Pechini method) and nitrate method. ${ }^{39}$ For both methods, stoichiometric ratio of metal nitrates $\left(\mathrm{Sr}\left(\mathrm{NO}_{3}\right)_{2}\left(99+\%\right.\right.$, Sigma-Aldrich), $\mathrm{Ba}\left(\mathrm{NO}_{3}\right)_{2}\left(99+\%\right.$, Sigma-Aldrich), $\mathrm{Fe}\left(\mathrm{NO}_{3}\right)_{3} \cdot 9 \mathrm{H}_{2} \mathrm{O}(98+\%$, Acros Organics)) were mixed and continuously stirred in minimal amount of water (just enough to dissolve the nitrates) at room temperature for 30 minutes. For the citrate-nitrate method, aqueous citric acid (2 M) was then added to the nitrate solution and stirred for another 30 minutes. The amount of citrate to total metal ions is in a 2:1 molar ratio. Afterwards, the solution was heated to $368 \mathrm{~K}$ until dry, followed by further heating up to $603 \mathrm{~K}$ on a hot plate at $10 \mathrm{~K}$ increments. At the highest temperature, decomposition of nitrates is complete in the nitrate case and auto-combustion would also have had taken place in the citrate-nitrate case. Samples were calcined in a box furnace at $1273 \mathrm{~K}$ for 6 hours in air 
with a ramp rate of $5 \mathrm{~K} / \mathrm{min}$. The samples were cooled to room temperature by switching off the furnace. Some of the samples were further soaked in $0.02 \mathrm{M}$ citric acid at $323 \mathrm{~K}$ for at least 30 min under continuous stirring to redissolve any unwanted carbonate byproducts. The supernatant was then discarded and the sample was rinsed with water for three times. After drying at $363 \mathrm{~K}$, the sample at the bottom was taken to the box furnace for calcination at $1273 \mathrm{~K}$ for 6 hours in air with a ramp rate of $5 \mathrm{~K} / \mathrm{min}$.

$\mathrm{SrFeO}_{3}, \mathrm{BaBiO}_{3}$ and $\mathrm{BaCoO}_{3}$ were synthesised by mixing solids of metal oxides and carbonates ( $\mathrm{SrO}$ (99.9\%, Sigma-Aldrich), $\mathrm{Fe}_{2} \mathrm{O}_{3}$ (95+\%, Sigma-Aldrich), $\mathrm{Bi}_{2} \mathrm{O}_{3}$ (99.999\%, Sigma-Aldrich), $\mathrm{BaCO}_{3}$ (puriss p.a., Sigma-Aldrich), $\mathrm{CoCO}_{3} \cdot \mathrm{xH}_{2} \mathrm{O}$ (43-47\% Co, SigmaAldrich)) with a mortar and pestle for at least 25 minutes. $\mathrm{SrFeO}_{3}$ and $\mathrm{BaCoO}_{3}$ were calcined at the same conditions as mentioned above while $\mathrm{BaBiO}_{3}$ was calcined in air at $1073 \mathrm{~K}$ for 24 hours.

We used x-ray powder diffraction (XRD, Panalytical Empyrean with $\mathrm{Cu}$ K $\alpha$ radiation) to identify the phases in the synthesised materials. The mass variation with respect to temperature and different gaseous environment was studied using a thermogravimetric analyser (TGA) (Mettler Toledo TGA/DSC-1). Air, $\mathrm{N}_{2}$ or $\mathrm{CO}_{2}$ were used as reactive gases $(50 \mathrm{~mL} / \mathrm{min}, 293 \mathrm{~K})$, while $\operatorname{Ar}(50 \mathrm{~mL} / \mathrm{min}, 293 \mathrm{~K})$ was used as a protective and purge gas. We carried out a separate experiment to study the effect of dilution from the protective and purge gases using the decomposition of $\mathrm{CaCO}_{3}$ in various partial pressure of $\mathrm{CO}_{2}$ (balanced with $\mathrm{N}_{2}$ ) in the reactive gas stream. We deduced the dilution factor by comparing the results with well-established literature values. ${ }^{40,41}$ Our results showed that the average dilution factor was 0.727 , i.e. the effective $p_{\mathrm{CO}_{2}}$ was $7.27 \times 10^{4} \mathrm{~Pa}$ for using pure $\mathrm{CO}_{2}$ as reactive gas and the effective $p_{\mathrm{O}_{2}}$ was $1.5 \times 10^{4} \mathrm{~Pa}$ for air as reactive gas.

To determine material characteristics such as the equilibrium temperature $\left(\mathrm{T}_{\text {eq }}\right)$, oxygen capacity $(\delta \mathrm{m})$ and reversibility, we performed a temperature ramp experiment in the TGA, typically at ramp rate of $20 \mathrm{~K} / \mathrm{min}$ (sample masses are detailed in Table $\mathrm{S} 1$ of the Supporting Information). We can also obtain kinetic information and isothermal oxygen capacity $(\delta \mathrm{m})$ 
in a pressure swing experiment where we change the $p_{\mathrm{O}_{2}}$ by switching between gases at a fixed temperature. Blank measurements taken without any samples were subtracted from the data to correct for buoyancy effects. The outlet gas from TGA was further analysed using a Fourier transform infrared spectrometer (FTIR) (Thermo Scientific Nicolet iS10) to monitor the production of any $\mathrm{CO}_{2}$.

\section{Results}

\section{Summary of screened materials and their calculated properties}

The screening of the Materials Project database for compounds within the $A-B-\mathrm{O}_{2}$ open phase diagrams found 5501 distinct compounds able to undergo redox reactions, with 20861 distinct redox reactions found for these compounds, with some compounds being able to undergo multiple different reactions at different $\mu_{\mathrm{O}_{2}}$. For compounds with multiple possible reactions, the one with the largest (least negative) $\mu_{\mathrm{O}_{2}}$ was chosen as the representative reaction for that compound, as this generally corresponds to the experimentally observed reaction for materials with previously recorded data. After further restricting these oxidation reactions to those that occur between $1 \times 10^{2} \mathrm{~Pa}<p_{\mathrm{O}_{2}}<1 \times 10^{6} \mathrm{~Pa}$ and 150 $\mathrm{K}<T<1700 \mathrm{~K}, 2216$ compounds were found to undergo reactions within the desired range. This represents the largest such screening of materials for chemical looping applications. The full results are available in the open data repository for this publication at https://www.repository.cam.ac.uk.

Using the relative energies of the reactant and product phases for each screened reaction it was possible to compute a value for $\Delta H_{\text {reduction. }}$ Furthermore, from the stoichiometry of the reaction it was also possible to determine a gravimetric $\mathrm{O}_{2}$ capacity $\left(\mathrm{g}_{2}\right.$ absorbed $\left./ \mathrm{g}_{\text {material }}\right)$ as a measure of the maximum $\mathrm{O}_{2}$ release by a chemical looping process using the material. These two parameters were plotted for each of the screened reactions against the predicted redox temperature at $p_{\mathrm{O}_{2}}=2.1 \times 10^{4} \mathrm{~Pa}$ in Figure 1 . 
While it can be seen that there are a handful of materials with a very high gravimetric capacity $\left(>1.5 \mathrm{~g}_{2}\right.$ absorbed $\left./ \mathrm{g}_{\text {material }}\right)$, these are mostly reactions involving one or more gaseous components that would be unsuitable for chemical looping applications. The vast majority of solid oxide materials have similarly low gravimetric capacities $\left(<0.5 \mathrm{~g}_{2}\right.$ absorbed $\left./ \mathrm{g}_{\text {material }}\right)$, leading us to consider other more discerning factors in selecting initial candidate materials to test.

There are a relatively large number of materials (292) that undergo solid single phase to single phase redox reactions, which is desirable in terms of minimising the reaction complexity and the total number of phases present at any point of the reaction. With multicomponent systems additional challenges are possible due to phase segregation over multiple cycles.

This subset was further winnowed down to 108 materials after excluding materials containing expensive or toxic elements including $\mathrm{Ag}, \mathrm{As}, \mathrm{Au}, \mathrm{Cd}, \mathrm{Cr}, \mathrm{Hg}, \mathrm{Ir}, \mathrm{Os}, \mathrm{Pb}, \mathrm{Pd}, \mathrm{Pt}$, $\mathrm{Re}, \mathrm{Rh}, \mathrm{Ru}, \mathrm{Te}$, as well as reactions that involved non-oxide materials after reduction, which would preclude their use in a large scale process. A summary of these remaining materials can be found in Table S2 of the Supporting Information.

Within this set of materials we were particularly interested in a series of materials that were based on the reduction of perovskite materials of the general formula $A B \mathrm{O}_{3}$. These materials are able to accommodate a range of oxygen stoichiometries without large discontinuous structural changes, making them ideal for use in chemical looping. Additionally, they are made from elements with a high abundance, giving them some possibility for use in scaled up processes. As the database only includes fully stoichiometric materials, all theoretical candidate materials have no oxygen non-stoichiometry, and the actual oxygen content of synthesised $\mathrm{SrFeO}_{3-\delta}$ is reported later in the experimental results.

Perovskite materials are relatively straightforward to synthesise, and the ability to compare several different materials with similar structures from the screening is desirable for initial validity testing, as it minimises other variables such as structural and morphological differences. Of these perovskite materials found in the screening, $\mathrm{SrBiO}_{3}$ and $\mathrm{SrMnO}_{3}$ were 


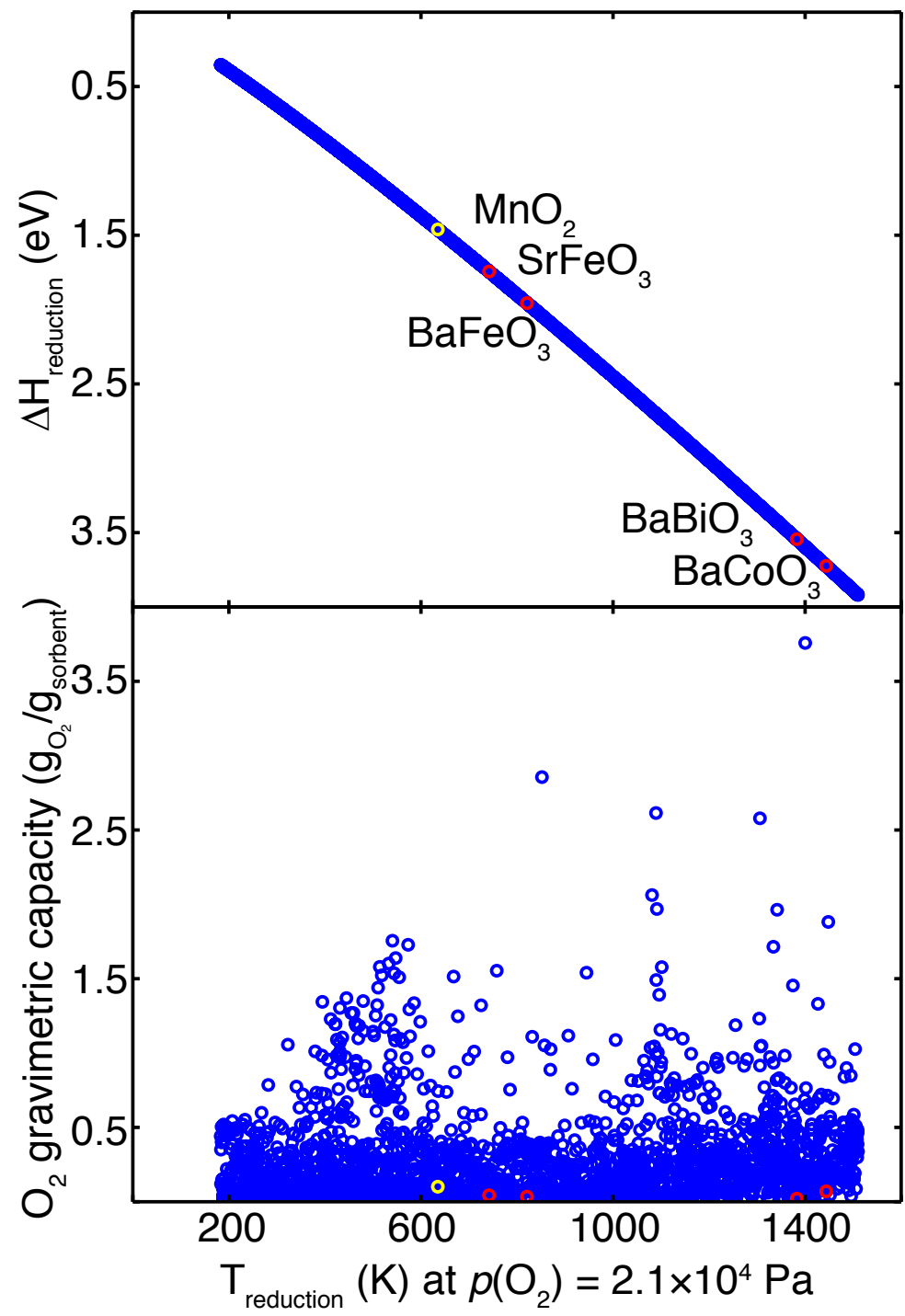

Figure 1: Overview of results from the screening of the Materials Project database for compounds that undergo redox reactions. Each data point represents the reduction reaction for each distinct compound with the largest $\mu_{\mathrm{O}_{2}}$. The predicted reduction temperature at $p_{\mathrm{O}_{2}}=2.1 \times 10^{4} \mathrm{~Pa}$ for each reaction is plotted against $\Delta H_{\text {reduction }}$ (upper) and $\mathrm{O}_{2}$ gravimetric capacity (lower). 
not included in the initial set of candidates, with the former requiring very high oxygen pressures $\left(1 \times 10^{7} \mathrm{~Pa}\right)^{42}$ which is beyond our synthetic capabilities, and the latter forming a different structure at room temperature. ${ }^{43}$

We note however that there are several interesting materials that we hope to include in the second wave of experimental testing, either because of their chemical composition being economically reasonable, or their predicted redox thermodynamics lying within a suitable range for an optimised chemical looping process. These include $\mathrm{MnPO}_{4},{ }^{44} \mathrm{Sr}_{2} \mathrm{Cu}_{2} \mathrm{O}_{5}$ and the family of materials with the general formula $\mathrm{ABiO}_{3}(A=\mathrm{Li}, \mathrm{Na}$ and $\mathrm{K})$.

The selected candidate materials are summarised in Table 1 and their calculated oxidation equilibrium curves are plotted in Figure 2. They are also highlighted in Figure 1, with some of the materials having very similar oxidation temperatures to the $\mathrm{MnO}_{2}-\mathrm{Mn}_{2} \mathrm{O}_{3}$ system. Table 1: Theoretically derived reduction reaction parameters for the preliminary candidates obtained from the screening.

\begin{tabular}{|c|c|c|c|}
\hline Compound & $\begin{array}{c}\Delta H_{\text {reduction }} \\
\mathrm{kJ} \mathrm{mol}^{-1}\end{array}$ & $\begin{array}{c}\mathrm{O}_{2} \text { capacity } \\
\mathrm{g}_{2} / \mathrm{g}_{\text {sorbent }}\end{array}$ & Reaction \\
\hline $\mathrm{SrFeO}_{3}$ & 168.3 & 0.044 & $4 \mathrm{SrFeO}_{3} \longrightarrow 2 \mathrm{Sr}_{2} \mathrm{Fe}_{2} \mathrm{O}_{5}+\mathrm{O}_{2}$ \\
$\mathrm{BaFeO}_{3}$ & 188.8 & 0.034 & $4 \mathrm{BaFeO}_{3} \longrightarrow 2 \mathrm{Ba}_{2} \mathrm{Fe}_{2} \mathrm{O}_{5}+\mathrm{O}_{2}$ \\
$\mathrm{BaBiO}_{3}$ & 342.0 & 0.021 & $4 \mathrm{BaBiO}_{3} \longrightarrow 2 \mathrm{Ba}_{2} \mathrm{Bi}_{2} \mathrm{O}_{5}+\mathrm{O}_{2}$ \\
$\mathrm{BaCoO}_{3}$ & 359.3 & 0.070 & $2 \mathrm{BaCoO}_{3} \longrightarrow 2 \mathrm{BaCoO}_{2}+\mathrm{O}_{2}$ \\
\hline
\end{tabular}

\section{Characterisation and initial experimental studies of candidate ma- terials}

To determine the validity of our materials screening method for the selected candidate materials, we performed TGA temperature ramp experiments in air. We define the experimental equilibrium temperature $\left(\mathrm{T}_{\text {eq, expt }}\right)$ to be the onset of significant mass loss upon heating, and these values can then be compared to the corresponding equilibrium temperatures predicted from the theoretical screening. Figure 3 shows the percentage change of sample mass, normalised by the mass of oxidised sample at low temperature $\left(\mathrm{m}_{\mathrm{o}}\right)$, with respect to temperature. 


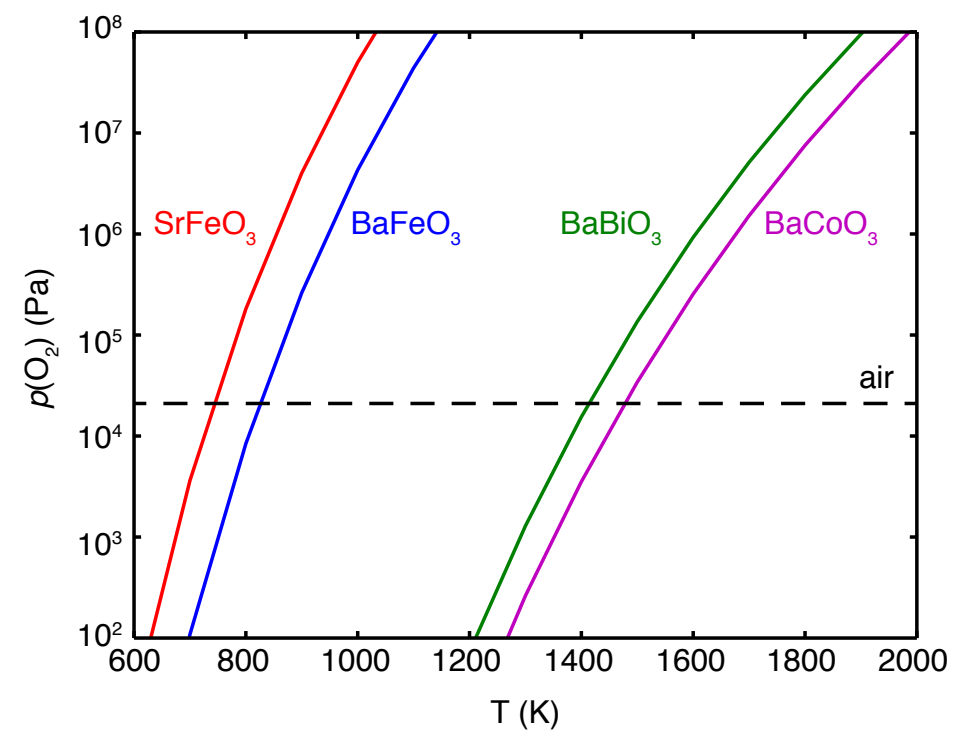

Figure 2: Calculated equilibrium $p_{\mathrm{O}_{2}}$ of shortlisted materials at various temperatures.

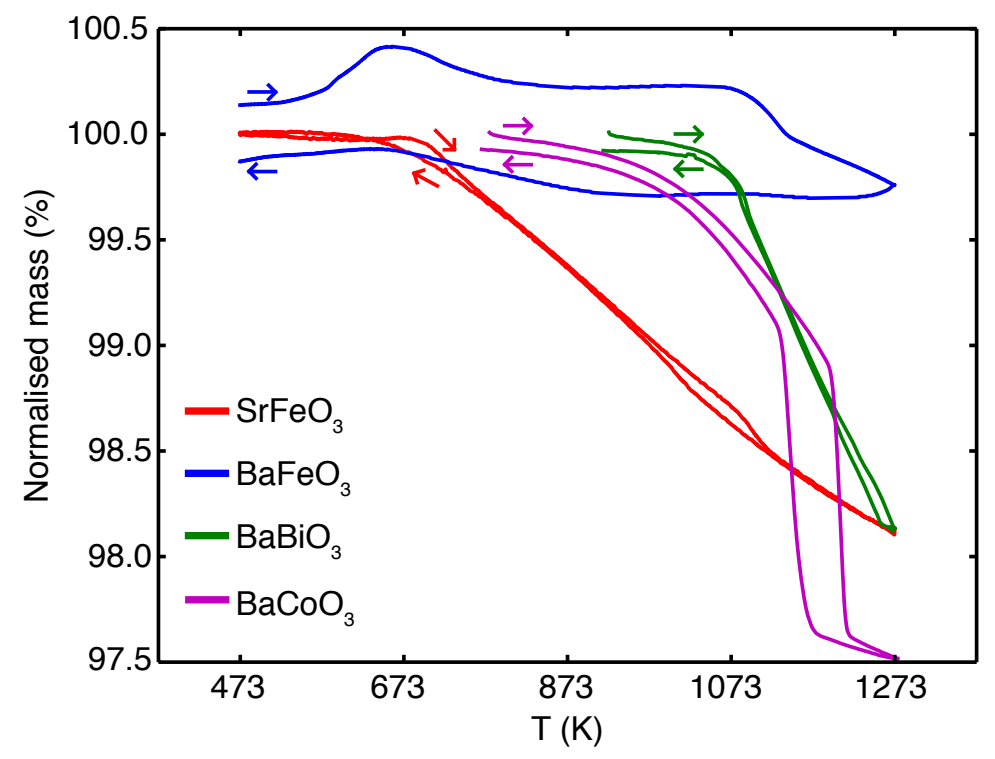

Figure 3: TGA experiments for each of the candidate materials carried out under $p_{\mathrm{O}_{2}}=$ $1.5 \times 10^{4} \mathrm{~Pa}$ with a ramp rate of $20 \mathrm{~K} / \mathrm{min}$. 
We disregarded results from the first ramp cycle up to $1273 \mathrm{~K}$ because the mass loss in its heating segment was always larger than the subsequent cooling segment and further heating cycles, with the latter two replicating each other. From FTIR, we observed that the extra mass loss was associated with $\mathrm{CO}_{2}$ production, suggesting the decomposition of possible carbonates. This is also supported by XRD analysis which showed the presence of small amounts of impurity $\mathrm{SrCO}_{3}$ and $\mathrm{BaCO}_{3}$ phases in most of the fresh samples. Since oxides of alkali earth metals are known to carbonate easily, any metal oxides that did not successfully react to form perovskite would probably combine with $\mathrm{CO}_{2}$ in air to form carbonates during cooling in the calcination process. Therefore a decarbonation cycle immediately before a measurement is essential and was employed for consistency.

Three of the four candidate materials were observed to oxidise reversibly in air, however, we were not able to obtain $\mathrm{T}_{e q}$ for $\mathrm{BaFeO}_{3}$, which showed minimal (if any) redox reaction with the small amount of activity more likely to originate from residual $\mathrm{BaO}$ in the sample. This is consistent with previous findings and probably related to its slow re-oxidation. ${ }^{45,46}$ There are also clear differences between the rate of reduction between the other three samples; $\mathrm{SrFeO}_{3}$ continually releases oxygen slowly over a wide range of temperatures $(\sim 673-1273 \mathrm{~K})$, while $\mathrm{BaBiO}_{3}$ releases oxygen much more quickly over a more restricted temperature range. These differences are more likely due to different relative stabilities of oxygen non-stiochiometric phases between the fully oxidised and reduced forms. For instance, $\mathrm{SrFeO}_{3-\delta}$ is known to have many stable phases between $0<\delta<0.5$ each of which would be a stable phase along the oxygen release curve, ${ }^{47}$ with the small amount of oxygen released between each transition leading to a slow continuous release. In the $\mathrm{BaBiO}_{3}$ material, the reaction appears to progress more quickly, while $\mathrm{BaCoO}_{3}$ appears to display behaviour that is a mix between the two other materials, with an initially slow continuous oxygen release followed by a more rapid transition. This may reflect that there is a limited range of stability for oxygen nonstoichiometry with small $\delta$ values for $\mathrm{BaBiO}_{3}$ and $\mathrm{BaCoO}_{3}$, beyond which the material transforms quickly into the stoichiometric $\mathrm{Ba}_{2} \mathrm{Bi}_{2} \mathrm{O}_{5}$ or $\mathrm{BaCoO}_{2}$ phase. 
In order to extract kinetic parameters it is neccessary to consider the effect of heat and mass transfer, with the analysis complicated by the fact that the kinetic driving force is the difference between the $p_{\mathrm{O}_{2}}$ seen by the sample and the local equilibrium value (which is changing). Even in the absence of temperature lags, the rate of oxygen release can be limited by the chemical equilibrium. Here, establishing the kinetics is beyond the scope of this paper, but some observations can be made on the rates. The lack of hysteresis upon cooling for $\mathrm{SrFeO}_{3-\delta}$ in Figure 3 suggests that the rate of mass loss is controlled by the equilibrium, i.e. at each temperature, the heating rate is slow enough that at a given temperature, the rate is fast enough to allow the sample to come to a stoichiometry which is in equilibrium with the local bulk oxygen concentration. Further initial kinetic experiments are shown in Figure S1 of the Supporting Information, using heating rates from 5 to $20 \mathrm{~K}$ $\min ^{-1}$ with a much smaller sample mass, also show neglible influence of heating rate on the mass change. The lack of dependence on heating rate in these experiments also suggests the sample is able to adjust its stoichiometry to match the local oxygen concentration quickly, and therefore determining kinetic parameters from non-isothermal TGA experiments may be difficult. These experiments also suggest that under the conditions used in this paper thermal lag is minimal.

Comparing these experimental values with the theoretically predicted values, we found that they are in reasonable agreement within the approximations of our theoretical methodology, especially in the intermediate temperature range (Figure 4). This validates the accuracy of our material screening method, and supports its utility in identifying oxygen carrier materials in the intermediate temperature regime. It should be noted however that the theoretically determined equilibrium temperatures are for a two phase reaction that only includes the stoichiometric phases; in reality it is known that there are many stable intermediate members formed upon reducing perovskites $\left(A B \mathrm{O}_{3-\delta}\right)$ where $0<\delta<0.5$, and the experimentally determined equilibrium temperatures could very well correspond to one or more of these intermediate transitions. The intermediate phases are likely to have similar 
energies to the parent perovskite phase, but even small differences in their ground state energies would lead to deviations from our theoretical predictions. Additionally, in the case of $\mathrm{BaBiO}_{3}$ and $\mathrm{BaCoO}_{3}$, even though there may not be as many stable intermediate phases, metastable states with different $\delta$ values could very well be accessed during the reaction.

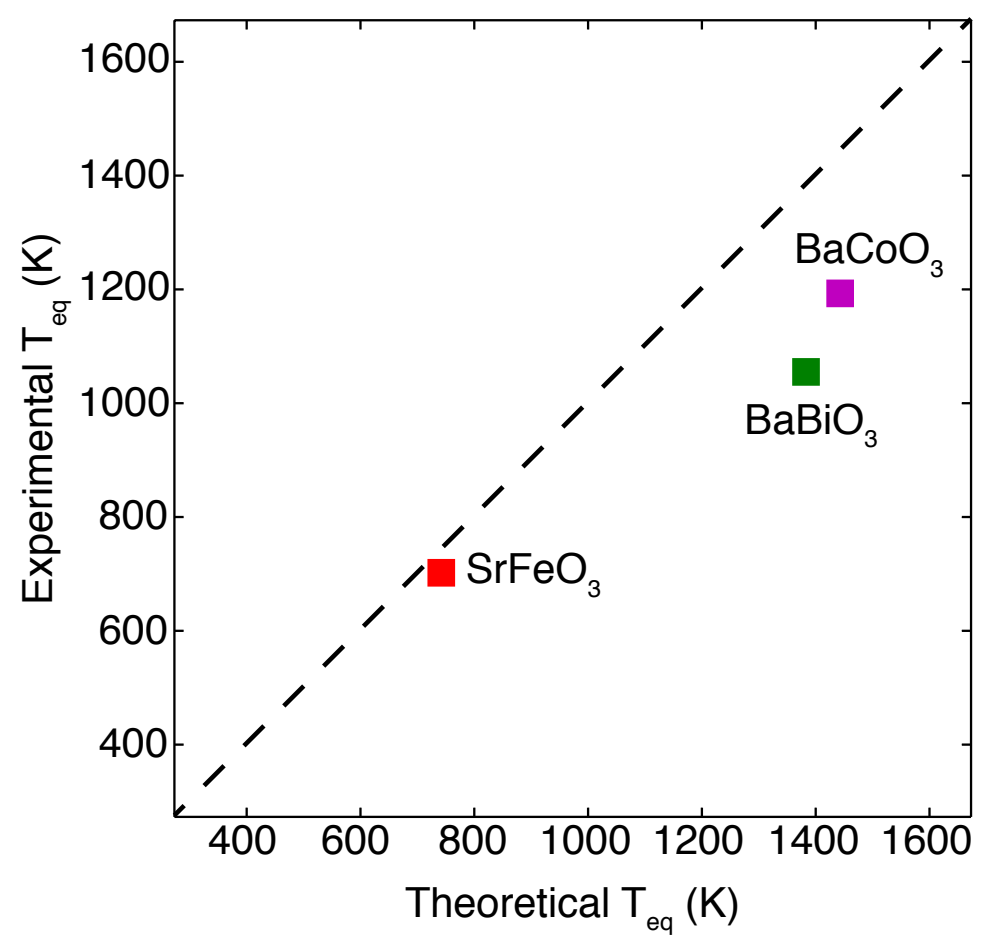

Figure 4: Comparison between theoretical equilibrium temperatures from the screening, and those obtained from TGA experiments, both under $p_{\mathrm{O}_{2}}=1.5 \times 10^{4} \mathrm{~Pa}$.

These initial results also found that the $\mathrm{SrFeO}_{3}-\mathrm{Sr}_{2} \mathrm{Fe}_{2} \mathrm{O}_{5}$ system has redox activity in exactly the right regime that we were searching in for new materials for CLC: its experimental equilibrium temperature of $702 \mathrm{~K}$ under $p_{\mathrm{O}_{2}}=1.5 \times 10^{4} \mathrm{~Pa}$ is below the maximum temperature of $823 \mathrm{~K}$ for an optimal industrial CLC process, and at partial pressures close to that of air. Furthermore, it is comprised of relatively cheap and abundant elements that would be suitable for use on a large scale. Based on these initial results we investigated the redox cycling properties of $\mathrm{SrFeO}_{3-\delta}$ further to determine its viability. The microstructure of $\mathrm{SrFeO}_{3-\delta}$ is shown in Figure $\mathrm{S} 2$ of the Supporting Information, showing minimal porosity as expected of an oxide sintered at high temperatures. We were also interested in the influence 
of impurities on the redox cycling of the material, and as such compared its performance to the multiphase sample that was the result of the initial synthesis. The x-ray diffractograms of the multiphase sample consisting of $\mathrm{SrFeO}_{3-\delta}$ and $\mathrm{Sr}_{3} \mathrm{Fe}_{2} \mathrm{O}_{7}$ (top), and pure $\mathrm{SrFeO}_{3-\delta}$ (middle) samples are shown in Figure 5, along with the sample remaining after reduction in $\mathrm{N}_{2}$ (bottom), confirming that $\mathrm{Sr}_{2} \mathrm{Fe}_{2} \mathrm{O}_{5}$ was the experimental end product, matching the predicted reaction. XRD diffraction patterns confirming similar agreement between the experimental and theoretically predicted redox products for $\mathrm{BaBiO}_{3}$ and $\mathrm{BaCoO}_{3}$ are shown in Figure $\mathrm{S} 3$ of the Supporting Information.

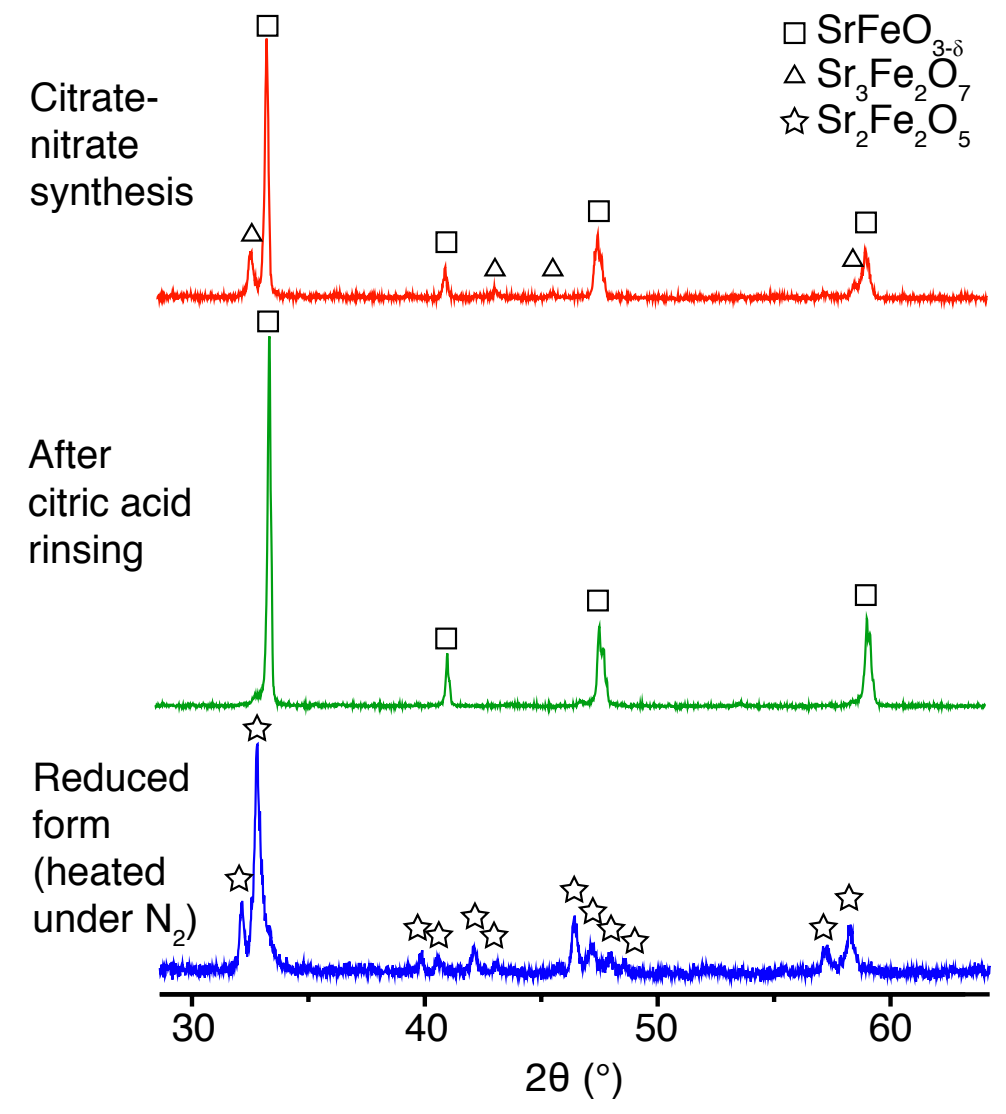

Figure 5: XRD diffractograms $(\lambda=1.5405 \AA)$ for different $\mathrm{SrFeO}_{3-\delta}$ samples. Top: sample prepared by the citrate-nitrate method, containing both $\mathrm{SrFeO}_{3-\delta}$ and $\mathrm{Sr}_{3} \mathrm{Fe}_{2} \mathrm{O}_{7}$ phases. Middle: sample after rinsing with citric acid, which contains only $\mathrm{SrFeO}_{3-\delta}$. Bottom: citricacid rinsed sample after reduction under $\mathrm{N}_{2}$ in the TGA, containing only $\mathrm{Sr}_{2} \mathrm{Fe}_{2} \mathrm{O}_{5}$. 


\section{Oxygen production using isothermal pressure swing}

Taking advantage of the fact that $\mathrm{SrFeO}_{3-\delta}$ reduces to different extents at various $p_{\mathrm{O}_{2}}$ in the temperature range above $\sim 693 \mathrm{~K}$, we performed isothermal oxygen partial pressure swing experiments (abbreviated as pressure swing hereafter) to identify the optimal compromise between oxygen capacity $(\delta \mathrm{m})$ and kinetics. We firstly fully oxidised the sample in air for 30 minutes, followed by reduction in $\mathrm{N}_{2}$ for 30 minutes, then finally investigating its reversibility by reoxidising it in air for 30 minutes. The sample was subjected to isothermal pressure swings beginning at $723 \mathrm{~K}$ and then consecutively increasing to $1123 \mathrm{~K}$ in $100 \mathrm{~K}$ intervals. The selected temperatures for pressure swing studies and their maximum $\delta \mathrm{m}$ deduced from the temperature ramp experiments are shown in Figure 6(b). The amount of available oxygen $(\delta \mathrm{m})$ depends on the difference in non-stoichiometry of the perovskite at high $p_{\mathrm{O}_{2}}$ (air) and low $p_{\mathrm{O}_{2}}\left(\mathrm{~N}_{2}\right)$ at specific temperatures. This value maximises at around $923 \mathrm{~K}$. These $\delta \mathrm{m}$ measured under $\mathrm{N}_{2}$ are likely to be smaller than the pressure swing values as the samples might not have enough time to reach equilibrium during the ramp experiments.

For the pure sample, the maximum theoretical mass loss $\left(\delta \mathrm{m}_{\mathrm{th}}\right)$, i.e. if all $\mathrm{SrFeO}_{3-\delta}$ was reduced to $\mathrm{SrFeO}_{2.5}$, should be $4.18 \%$. However, the measured value from TGA $\left(\delta \mathrm{m}_{\text {expt }}\right)$ is only $1.89 \%$ in air (Figure 6), suggesting the complete reduction to $\mathrm{SrFeO}_{2.5}$ was not reached even at the highest attainable temperature in the TGA $(1273 \mathrm{~K})$. This is in fact the thermodynamic equilibrium since holding the sample at $1273 \mathrm{~K}$ for longer did not cause further mass loss, which agrees with previous studies. ${ }^{48-52}$ We also showed that this equilibrium is shifted when $\mathrm{N}_{2}$ was used to provide a lower $p_{\mathrm{O}_{2}}$, hence allowing further reduction of $\mathrm{SrFeO}_{3-\delta}$ to be achieved and giving a larger $\delta \mathrm{m}_{\text {expt }}$ of $2.23 \%$.

In order to fully determine the oxygen content of the as-synthesised $\mathrm{SrFeO}_{3-\delta}$ sample, we heated the sample in the TGA under a strong reducing $5 \% \mathrm{H}_{2}$ in $\mathrm{N}_{2}$ gas flow, and measured the total mass loss. As shown in the Figure S4 of the Supporting Information, this allowed us to calculate $\delta=0.22$ for the sample, giving an overall composition of $\mathrm{SrFeO}_{2.78}$ which is consistent with previous reports of synthesis in the literature. ${ }^{53}$ Given this reduced oxygen 
content in the synthesised sample, the pressure swing experiments therefore do indeed access most of the oxygen content of the material.
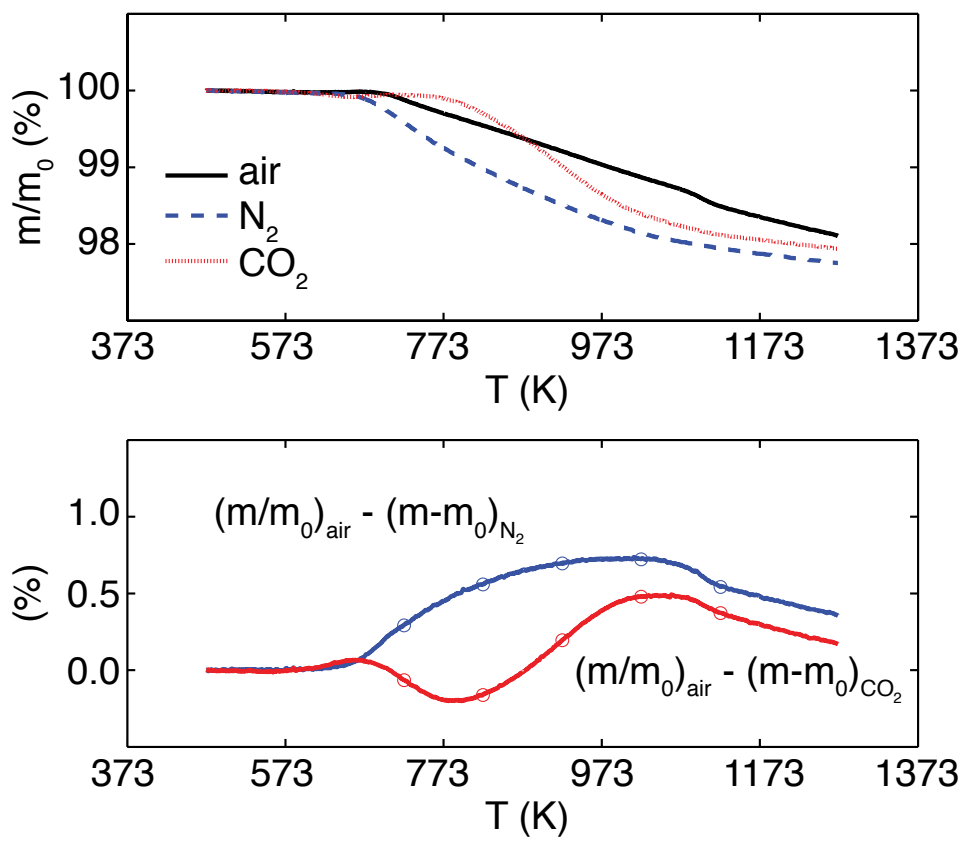

Figure 6: Top: normalised mass change of $\mathrm{SrFeO}_{3-\delta}$ during heating in various gaseous environment. Bottom: difference in normalised mass between reduction in air and $\mathrm{N}_{2} / \mathrm{CO}_{2}$ derived from top figure. The circles in the plot indicate temperatures selected for the pressure swing study.

As shown in the pressure swing results in Figure $7, \delta \mathrm{m}$ was indeed found to maximise at $923 \mathrm{~K}$, agreeing with the expectation from temperature ramp experiments. One should note that the sample mass is normalised on the mass of the air-oxidised sample at their respective temperatures for easy comparison of oxygen capacity. However, the starting materials were actually of different oxidation states, i.e. more reduced as temperature increased, and their differences are reflected in Figure S5 of the Supporting Information, where all masses are normalised on the mass of the most oxidised sample in air at low temperature $(473 \mathrm{~K})$. Therefore, the initial mass change before the gas switch is the sample coming into thermal and chemical equilibrium with the environment. We further investigated the kinetics in these studies and found that the reduction at lower temperatures $(\mathrm{T} \leq 923 \mathrm{~K})$ did not reach equilibrium within 30 min in $\mathrm{N}_{2}$. However, the reoxidation was very fast for all temperatures, 
where it was less than 5 min for $\mathrm{T} \geq 823 \mathrm{~K}$ and slightly longer at about 7 min for $723 \mathrm{~K}$. As the initial stage of reduction is faster, we might obtain more $\mathrm{O}_{2}$ per unit time if we cycle the sample at a higher rate instead of waiting longer to reach equilibrium. For example, if we perform two cycles of 5 min reduction in $\mathrm{N}_{2}$ with 5 min oxidation in air at $823 \mathrm{~K}$, then we get a cumulative mass loss of $1.28 \%$, which is more than if we were to reduced the sample in $\mathrm{N}_{2}$ for $30 \min (1.00 \%)$ (Figure 7 ).
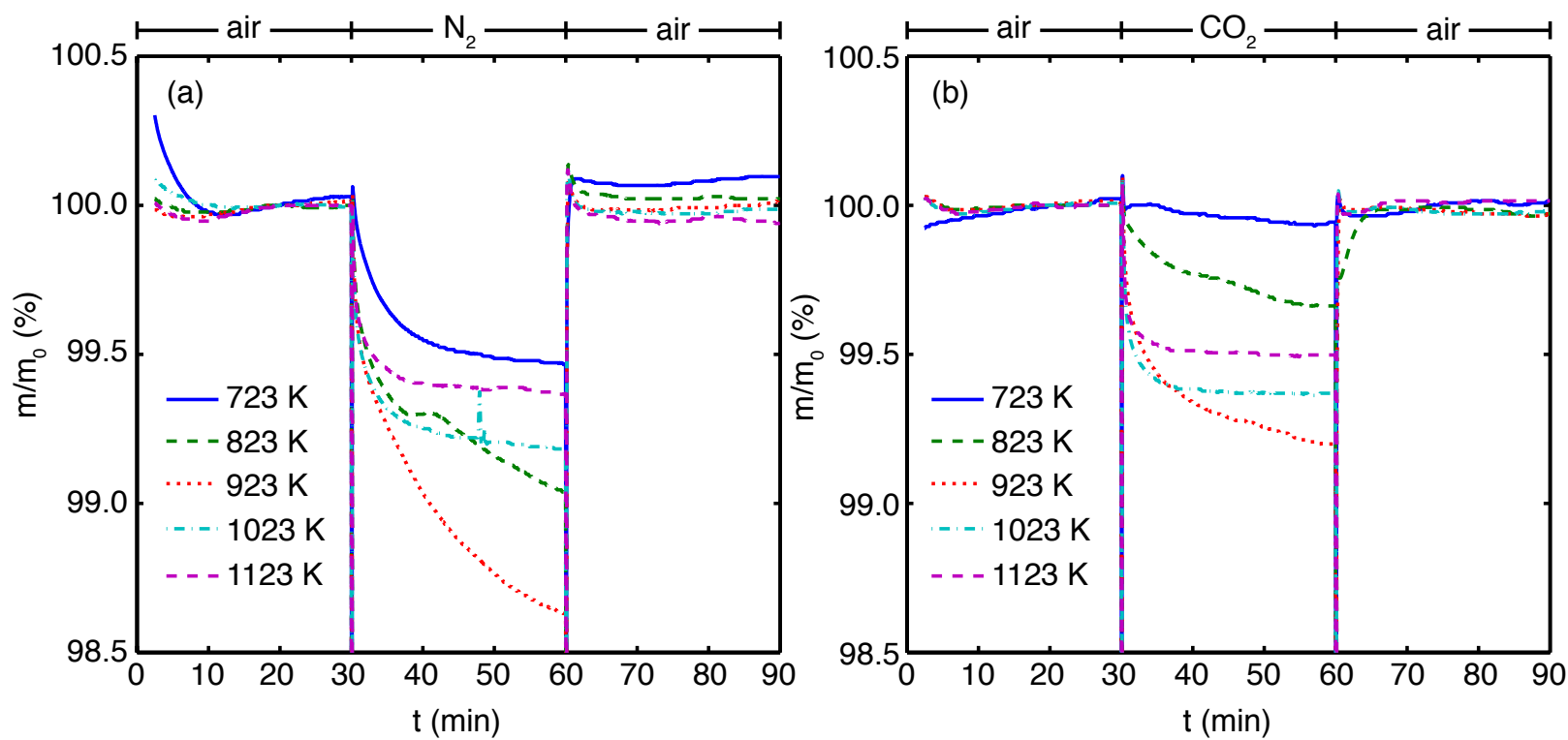

Figure 7: Pressure swing of sample with $\mathrm{SrFeO}_{3-\delta}$ in TGA for consecutive cycles of (a) 30min air - 30min $\mathrm{N}_{2}-30 \mathrm{~min}$ air and (b) 30min air - 30min $\mathrm{CO}_{2}-30 \mathrm{~min}$ air from $723 \mathrm{~K}$ to 1123 $\mathrm{K}$.

After demonstrating the feasibility of extracting gaseous $\mathrm{O}_{2}$ from $\mathrm{SrFeO}_{3-\delta}$ at intermediate temperature using pressure swing with $\mathrm{N}_{2}$, we proceeded to test the tendency for the sample to carbonate and/or reduce in pure $\mathrm{CO}_{2}$ (part of the chemical looping procedure). We investigated using $\mathrm{CO}_{2}$ instead of $\mathrm{N}_{2}$ as the reducing gas to drive oxygen production, which would result in pure $\mathrm{CO}_{2}$ after combustion for easy carbon capture. Note that this is a very economical process because the pure $\mathrm{CO}_{2}$ can be recycled as infeed so that no further material nor heat is required. As shown in Figure 6, the reduction of $\mathrm{SrFeO}_{3-\delta}$ in $\mathrm{CO}_{2}$ has a higher $\mathrm{T}_{\text {eq }}$ and smaller mass loss than under $\mathrm{N}_{2}$ and even air at temperatures below $\sim 873 \mathrm{~K}$. It then almost replicated the curve for $\mathrm{N}_{2}$ for temperatures above $1023 \mathrm{~K}$. The 
disproportionation of $\mathrm{CO}_{2}$ to $\mathrm{O}_{2}$ and $\mathrm{CO}$ in this temperature range would give a slightly higher $p_{\mathrm{O}_{2}}$ in $\mathrm{CO}_{2}$ than $\mathrm{N}_{2}$, but still much lower than that in air, and as such does not explain the above observed mass loss.

A possible explanation is that the surface adsorption of $\mathrm{CO}_{2}$ hinders the release of $\mathrm{O}_{2}$ from reduction. Bucher et al. showed with their TGA-MS result that the oxygen release from (Ba, $\mathrm{Sr})(\mathrm{Co}, \mathrm{Fe}) \mathrm{O}_{3-\delta}$ did not occur until the adsorbed $\mathrm{CO}_{2}$ was replaced by $\mathrm{O}_{2}$ as temperature increases. ${ }^{54}$ Similar observations were reported by Yan et al. with their $\mathrm{Ba}_{0.5} \mathrm{Sr}_{0.5} \mathrm{Co}_{0.8} \mathrm{Fe}_{0.2} \mathrm{O}_{3-\delta}$ based solid oxide fuel cell. ${ }^{55}$ They attributed the reduced current density in a $\mathrm{CO}_{2}$ environment to the hindered oxygen exchange by adsorbed $\mathrm{CO}_{2}$. This effect is lessened at higher temperature when oxygen adsorption is probably more favourable. As a result, $\mathrm{O}_{2}$ can only be produced through pressure swing at higher temperatures, i.e. at least $\sim 823 \mathrm{~K}$ as shown in Figure 7. Furthermore, our pressure swing result (Figure 7) is in agreement with the expectation from temperature ramp experiments (Figure 6) that $\delta \mathrm{m}$ in air- $\mathrm{CO}_{2}$ swing is smaller than that in air- $\mathrm{N}_{2}$ at lower temperatures but comparable at higher temperatures. This is again consistent with the explanation that $\mathrm{CO}_{2}$ adsorption dominates at lower temperature but diminishes as temperature increases. Nevertheless, our material has the advantage over many other Sr- or Ba-based perovskites that it does not carbonate in $\mathrm{CO}_{2}$ within the entire tested temperature range $(373-1273 \mathrm{~K}) .{ }^{56-58}$ Carbonation would imply a change in structure, hence possibly decreasing the mechanical robustness over long term cycling. Furthermore, the loss of $\mathrm{CO}_{2}$ during oxidation would reduce the carbon capture efficiency, assuming a reversible carbonation reaction (otherwise there would be a permanent loss of capacity).

\section{Carbonation of strontium ferrite at high temperatures}

We note that a very important factor in avoiding carbonation is to obtain a pure phase of $\mathrm{SrFeO}_{3-\delta}$. When we repeated the above cycling experiments with the multiphase sample containing $68 \% \mathrm{SrFeO}_{3-\delta}$ perovskite phase and $26 \% \mathrm{Sr}_{3} \mathrm{Fe}_{2} \mathrm{O}_{7}$ (the top sample in Figure 5), a distinctly different behaviour was observed for temperatures above around $1073 \mathrm{~K}$ in 
$\mathrm{CO}_{2}$ (Figure 8). The mass gain was very significant at these higher temperatures and we attributed that to the carbonation of $\mathrm{Sr}_{3} \mathrm{Fe}_{2} \mathrm{O}_{7}$, in contrast to Schmidt ${ }^{59}$ suggesting that this is due to the carbonation of $\mathrm{Sr}_{2} \mathrm{Fe}_{2} \mathrm{O}_{5}$, albeit with experiments conducted over a much longer timeframe. From temperature ramp experiments in $\mathrm{CO}_{2}$ for samples with different proportions of $\mathrm{Sr}_{3} \mathrm{Fe}_{2} \mathrm{O}_{7}$ and $\mathrm{SrFeO}_{3-\delta}$, we found that the maximum mass gain is directly proportional to the amount of $\mathrm{Sr}_{3} \mathrm{Fe}_{2} \mathrm{O}_{7}$ (Figure 9). The carbonation is also apparent from these samples being subjected to isothermal carbonation at $1123 \mathrm{~K}$ in $\mathrm{CO}_{2}$ for $30 \mathrm{~min}$. $\mathrm{XRD}$ spectra were taken upon fast-cooling in $\mathrm{CO}_{2}$, which should retain the carbonated phases. The spectrum revealed a significant amount of carbonated product, $\mathrm{SrCO}_{3}$, in the sample with $75 \% \mathrm{Sr}_{3} \mathrm{Fe}_{2} \mathrm{O}_{7}$ originally. On the other hand, $\mathrm{SrCO}_{3}$ was not obvious in the sample with $26 \% \mathrm{Sr}_{3} \mathrm{Fe}_{2} \mathrm{O}_{7}$, although a $1.33 \%$ mass gain was observed in the TGA. This is because this mass gain corresponds to less than $0.5 \%$ of $\mathrm{SrCO}_{3}$ in the product, which is close to the detection limit of XRD.
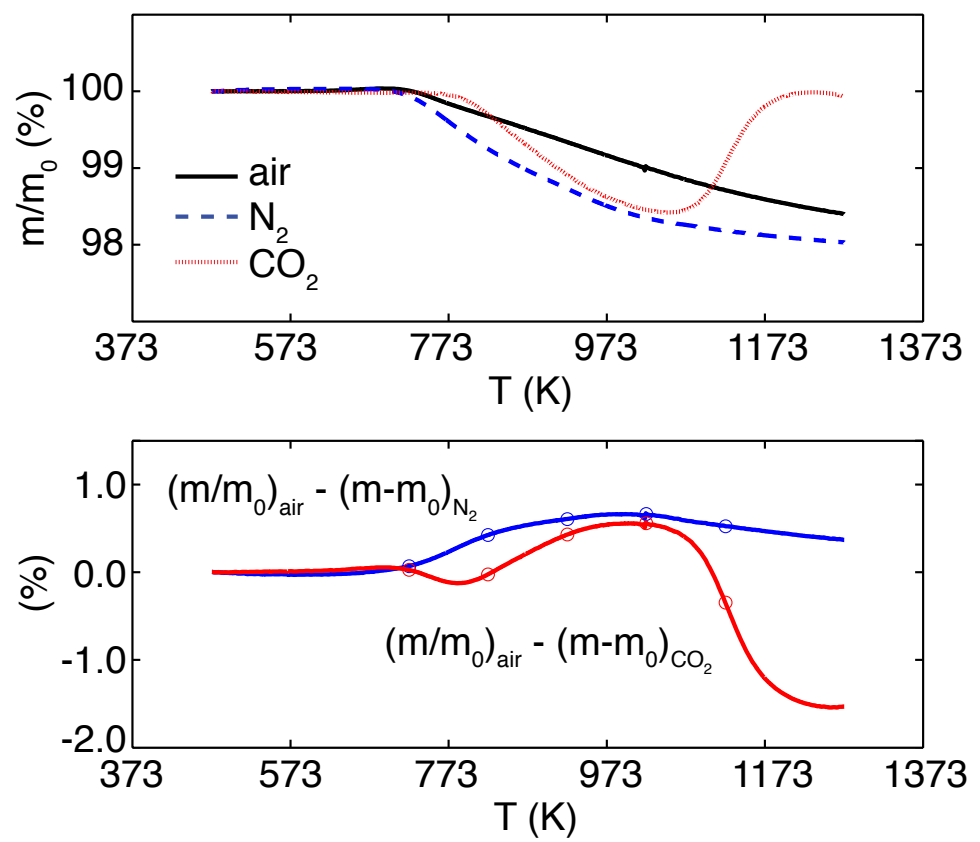

Figure 8: Top: normalised mass change of a sample containing $68 \% \mathrm{SrFeO}_{3-\delta}$ and $26 \%$ $\mathrm{Sr}_{3} \mathrm{Fe}_{2} \mathrm{O}_{7}$ during heating in various gaseous environment. Bottom: difference in normalised mass between reduction in air and $\mathrm{N}_{2} / \mathrm{CO}_{2}$ derived from (a). Open circles indicate temperatures selected for pressure swing study. 

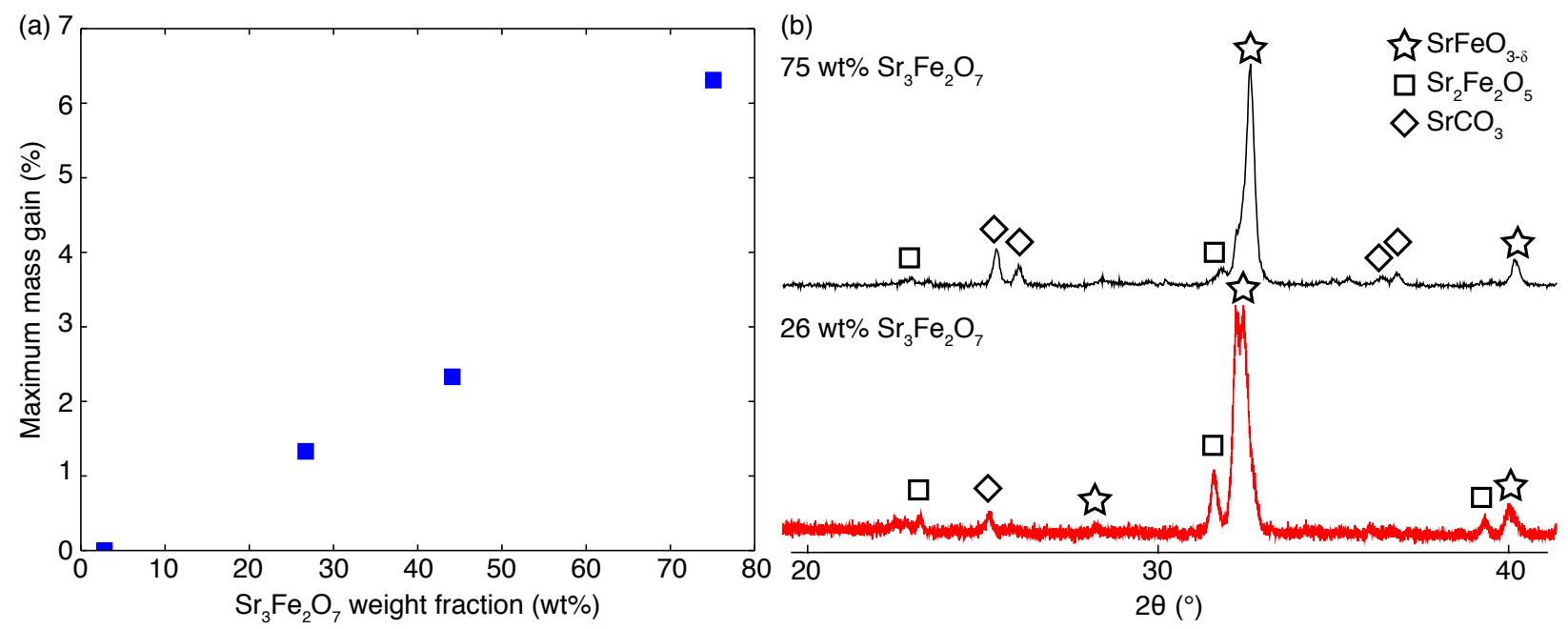

Figure 9: (a) Maximum mass gain in a temperature ramp experiment in $\mathrm{CO}_{2}$ for samples with various weight fraction of $\mathrm{Sr}_{3} \mathrm{Fe}_{2} \mathrm{O}_{7}$. (b) Ex-situ XRD spectra of samples with different weight fraction of $\mathrm{Sr}_{3} \mathrm{Fe}_{2} \mathrm{O}_{7}$ being carbonated at $1123 \mathrm{~K}$. Diamonds denote the $\mathrm{SrCO}_{3}$ phase, stars denote the $\mathrm{SrFeO}_{3-\delta}$ phase and squares denote the $\mathrm{Sr}_{2} \mathrm{Fe}_{2} \mathrm{O}_{5}$ phase.

A consequence of carbonation is that oxygen can no longer be produced efficiently by a pressure swing between air and $\mathrm{CO}_{2}$ at high temperatures. As shown in Figure 10, oxygen release (mass loss) is still noticeable at $1023 \mathrm{~K}$ when the oxidised sample was initially subject to a $\mathrm{CO}_{2}$ environment. At even higher temperatures $(1123 \mathrm{~K})$, carbonation occurred immediately in $\mathrm{CO}_{2}$ and the process was not fully reversible upon reoxidation in air. This shows the operation window is $\sim 823-923 \mathrm{~K}$ for an impure $\mathrm{SrFeO}_{3-\delta}$ sample, contaminated with secondary phase $\mathrm{Sr}_{3} \mathrm{Fe}_{2} \mathrm{O}_{7}$, to produce pure $\mathrm{CO}_{2}$ as flue gas in an oxyfuel combustion process.

\section{Robustness of strontium ferrite against redox cycles}

Next we investigated the reversibility of both pure and impure $\mathrm{SrFeO}_{3-\delta}$ during redox cycling. We performed isothermal pressure swing experiments at $823 \mathrm{~K}$ in two different reducing environments, $\mathrm{N}_{2}$ or $\mathrm{CO}_{2}$, while oxidation took place in air in both experiments. Each cycle consisted of a 15 min oxidation step followed by a 30 min reduction step. The bottom plots in Figure 11 show the maximum $\delta \mathrm{m}$ attained within each cycle. It can be seen that after the 

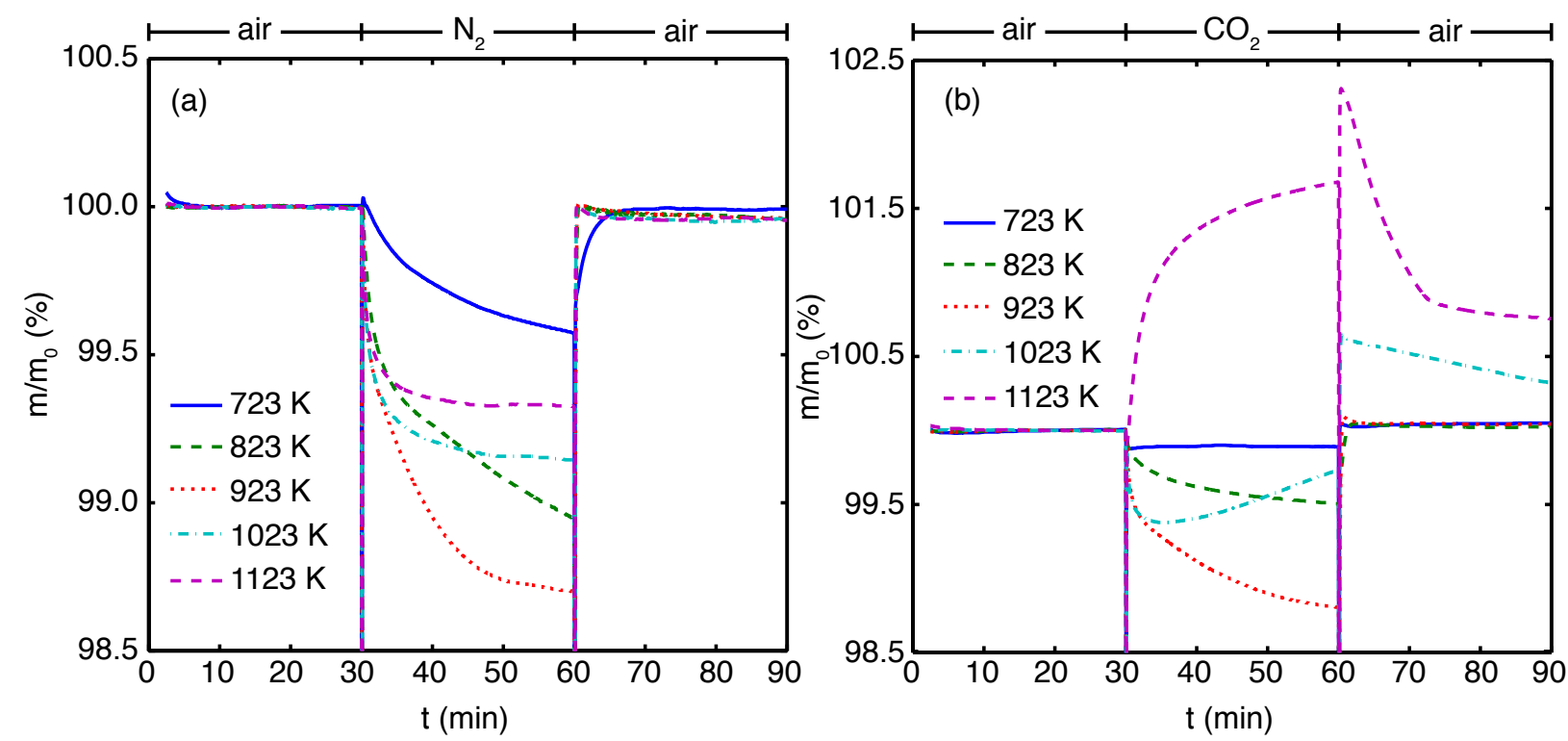

Figure 10: Pressure swing of sample with $68 \% \mathrm{SrFeO}_{3-\delta}$ and $26 \% \mathrm{Sr}_{3} \mathrm{Fe}_{2} \mathrm{O}_{7}$ in $\mathrm{TGA}$ for consecutive cycles of (a) 30min air - 30min $\mathrm{N}_{2}-30 \mathrm{~min}$ air and (b) 30min air - 30min $\mathrm{CO}_{2}$ $30 \mathrm{~min}$ air from $723-1123 \mathrm{~K}$.

fifth cycle, the $\delta \mathrm{m}$ stabilised with a consistent mass change between cycles, and the sample able to reoxidise to what appears to be a stable equilibrium mass on each cycle, for both pure (Figure $11 \mathrm{a})$ and multiphase $\left(68 \% \mathrm{SrFeO}_{3-\delta} / 26 \% \mathrm{Sr}_{3} \mathrm{Fe}_{2} \mathrm{O}_{7}\right.$, Figure $\left.11 \mathrm{~b}\right)$ samples. They are then fully reversible and produced a constant amount of oxygen over 20 cycles. On the other hand, material stability deteriorates during air- $\mathrm{CO}_{2}$ cycling (Figure $11 \mathrm{c}, \mathrm{d}$ and $\mathrm{f}$ ), with the exception of the pure sample cycled at $923 \mathrm{~K}$ (Figure 11 e). While the oxygen capacity decreased continuously for the multiphase sample at both 823 and $923 \mathrm{~K}$ (Figure $11 \mathrm{~d}$ and f), with only about $60 \%$ of the original capacity remaining after 20 cycles, $\delta \mathrm{m}$ of the pure sample remained relatively constant with the pure $\mathrm{SrFeO}_{3-\delta}$ sample maintaining an excellent $\delta \mathrm{m}=1 \%($ Figure $11 \mathrm{e})$.

We further noted a steady increase in the mass of multiphase material at $923 \mathrm{~K}$ (Figure 11 f). This is most likely due to gradual irreversible carbonation of $\mathrm{Sr}_{3} \mathrm{Fe}_{2} \mathrm{O}_{7}$ and $\mathrm{Sr}_{3} \mathrm{Fe}_{2} \mathrm{O}_{6}$ (the reduced form of $\mathrm{Sr}_{3} \mathrm{Fe}_{2} \mathrm{O}_{7}$ ) resulting in an accumulated mass gain. Since the mass gain per cycle is only about $0.06 \%$, it is not obvious in our pressure swing study that carbonation had taken place at $923 \mathrm{~K}$ (Figure 10). However, the cumulative effect becomes apparent after 20 
cycles. On the other hand, the part that is responsible for oxygen production, $\mathrm{SrFeO}_{3-\delta}$, was less susceptible to carbonation and therefore the cycling behaviour resembled that at $823 \mathrm{~K}$ where carbonation was less apparent (Figure $11 \mathrm{~d}$ ). The deterioration in oxygen production in $\mathrm{CO}_{2}$ is likely a result of irreversible carbonation, as well as reduction in active surface area due to carbonation as observed in some other oxygen carriers. The reversibility and long-term stability showed that the use of pure $\mathrm{SrFeO}_{3-\delta}$ in oxyfuel combustion for CLC at intermediate temperatures is promising. To further improve the material for industrial applications, further work can be done to maximise its $\delta \mathrm{m}$ and kinetics.

\section{Discussion}

While we chose to focus solely on the perovskite-brownmillerite reactions for further experimental analysis in the current work, the screening also revealed a number of other interesting insights, which we will briefly discuss here. Firstly, the positive results regarding $\mathrm{SrFeO}_{3-\delta}$ indicate that a useful strategy towards both stabilising well known binary oxide materials for CLC and reducing their equilibrium redox temperature can be to imbed that oxide within another matrix. In this case, the $\mathrm{Fe}^{3+}$ to $\mathrm{Fe}^{2+}$ redox couple activated in the reduction of $\mathrm{Fe}_{2} \mathrm{O}_{3}$ to $\mathrm{FeO}$ can be compared to the $\mathrm{Fe}^{4+}$ to $\mathrm{Fe}^{3+}$ redox reaction that is present in both the $\mathrm{SrFeO}_{3}$ and $\mathrm{BaFeO}_{3}$ systems. The binary oxide was calculated to have a predicted oxidation enthalpy of $5.51 \mathrm{eV}$ and an equilibrium reduction temperature in air of $1929 \mathrm{~K}$. In comparison, the values for $\mathrm{SrFeO}_{3}$ and $\mathrm{BaFeO}_{3}$ are $1.74 \mathrm{eV}$ and $1.96 \mathrm{eV}$ respectively, leading to much lower reduction equilibrium temperatures and more efficient use for CLC. The ability of ternary oxides to stabilise higher oxidation states is also seen when comparing the $\mathrm{MnO}_{2}-\mathrm{Mn}_{2} \mathrm{O}_{3}$ couple (predicted $T_{\text {oxidation,air }}=601 \mathrm{~K}$ ) with $\mathrm{SrMnO}_{3}-\mathrm{Sr}_{2} \mathrm{Mn}_{2} \mathrm{O}_{5}$ (predicted $\left.T_{\text {oxidation,air }}=1305 \mathrm{~K}\right)$. Furthermore, the more efficient cycling seen for $\mathrm{SrFeO}_{3-\delta}$ as compared to $\mathrm{Fe}_{2} \mathrm{O}_{3}$ may very well be due to the framework preventing further reduction reactions which are known to reduce capacity and lead to coke formation for the binary oxide system. ${ }^{11}$ So 
(a)

Pure $\mathrm{SrFeO}_{3}$
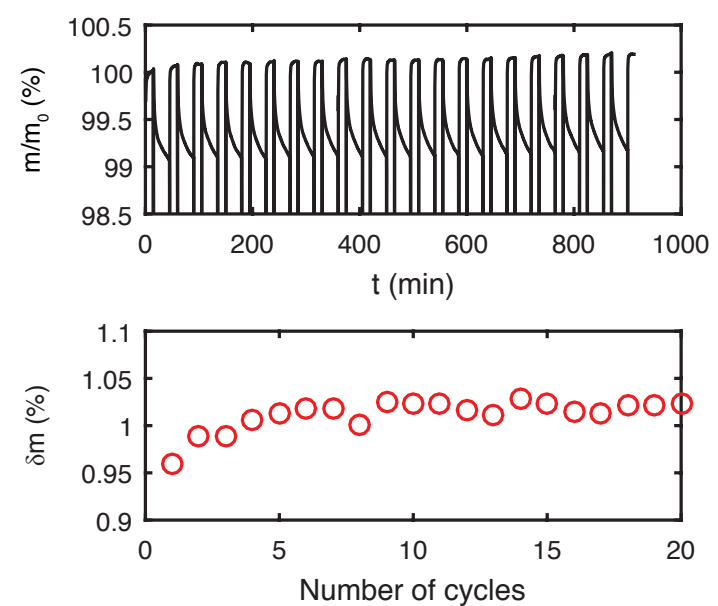

(c)
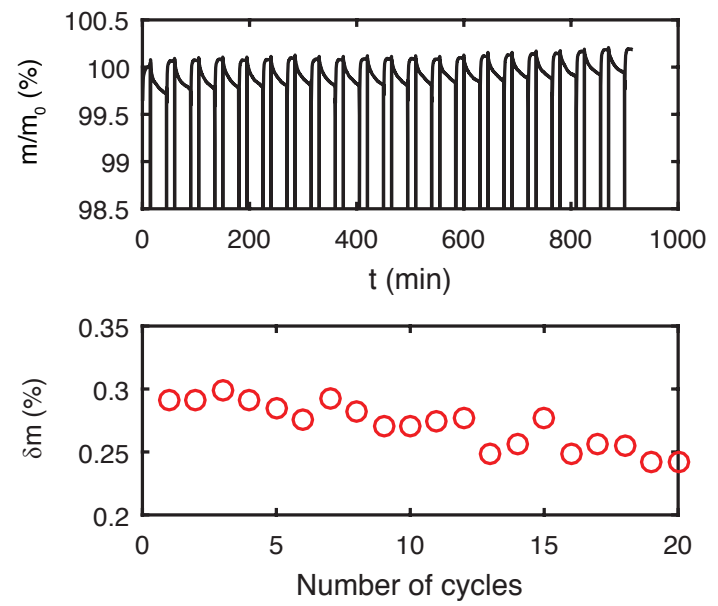

(e)
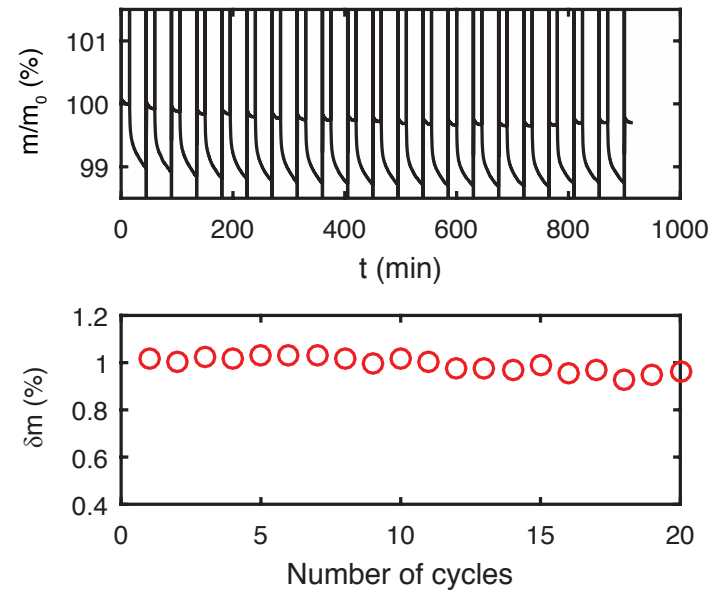

(b) $\quad$ Multiphase $\mathrm{SrFeO}_{3}$

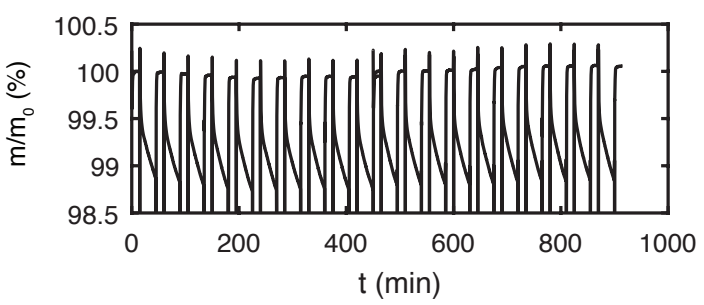

air/
$823 \mathrm{~K}$

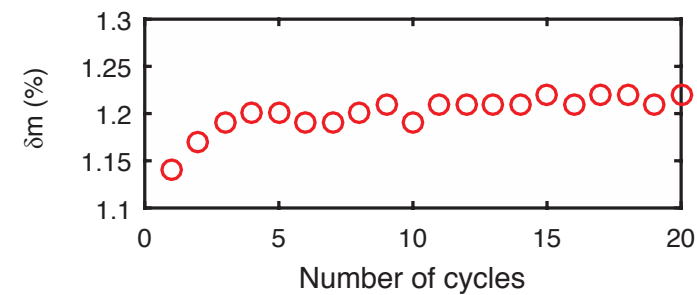

(d)

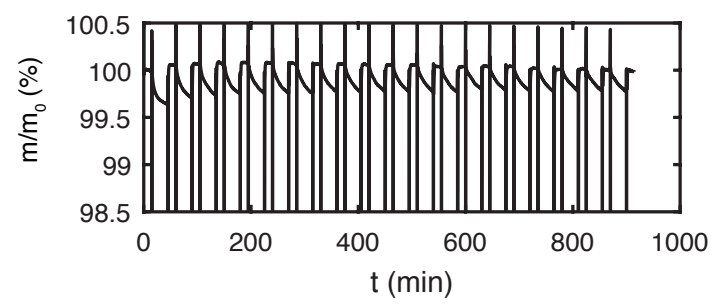

air/CO

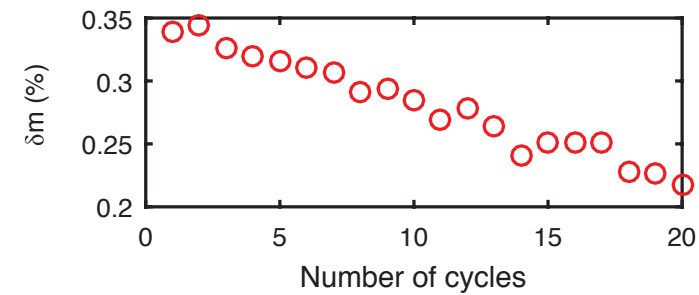

(f)
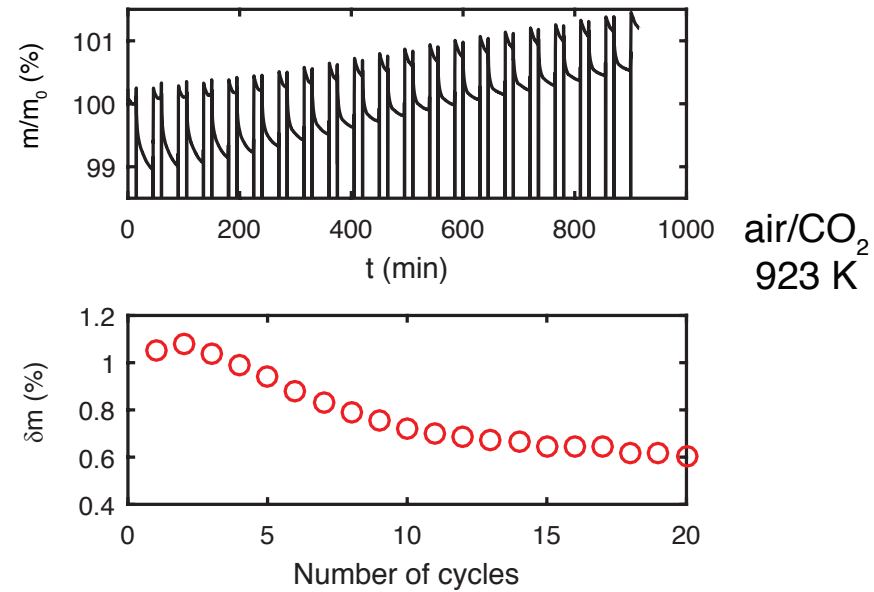

Figure 11: (a, c, e) Pure $\mathrm{SrFeO}_{3-\delta}$ sample (92\%) and (b, d, f) multiphase $\mathrm{SrFeO}_{3-\delta}$ $(68 \%) / \mathrm{Sr}_{3} \mathrm{Fe}_{2} \mathrm{O}_{7}(26 \%)$ sample subject to 20 cycles of (a \& b) 15 min air - 30 min $\mathrm{N}_{2}$ at $823 \mathrm{~K},(\mathrm{c} \& \mathrm{~d}) 15 \mathrm{~min}$ air $-30 \mathrm{~min} \mathrm{CO}_{2}$ at $823 \mathrm{~K}$ and $\left(\mathrm{e} \mathrm{\&} \mathrm{f)} 15 \mathrm{~min}\right.$ air $-30 \mathrm{~min} \mathrm{CO}_{2}$ at $923 \mathrm{~K}$ in TGA. The spikes seen at the beginning of each cycle are caused by perturbations in the balance caused by changes in gas flow when the gases are switched. 
a rational design strategy could be to find suitable ternary analogues for known binary reactions that could lead to improved properties, choosing appropriate reactions that lead to a improvement in the energy efficiency.

An interesting observation that arises from the single phase to single phase subset of the screened reactions is the large number of rare earth (RE) chromates, manganates and vanadates that are present in the database with two distinct forms that we are able to simulate oxidation reactions between: $A B \mathrm{O}_{3}$ (where $A=\mathrm{RE}, B=\mathrm{Cr}, \mathrm{Mn}$ or $\mathrm{V}$ ) and $A B \mathrm{O}_{4}$ (for $B=\mathrm{Cr}$ or $\mathrm{V}$ ) or $A_{2} B_{2} \mathrm{O}_{7}$ (for $B=\mathrm{Mn}$ ). The predicted oxidation enthalpies for the three series are plotted in Figure 12. In all cases the more oxidised form is more stable, a trend that matches well with previous studies of the oxidation of binary RE oxides. ${ }^{60}$ Furthermore, the trend in magnitude of the energy difference between the two forms follows the trend in f-electron character, with the half-filled shell in Eu leading to a more stable divalent state compared to the usual trivalent preference in other REs, and a corresponding discontinuity in atomic radii and theoretical lattice parameters of Eu pnictides and chalcogenides; ${ }^{61}$ this discontinuity is mirrored here in the relative instability and therefore greatly reduced oxidation energies for the nominally $\mathrm{Eu}^{3+}$ phases $\mathrm{EuMnO}_{3}$ and $\mathrm{EuVO}_{3}$ compared to the other corresponding RE manganates and vanadates.

To understand the observed carbonation of the mixed phase sample containing both $\mathrm{SrFeO}_{3-\delta}$ and $\mathrm{Sr}_{3} \mathrm{Fe}_{2} \mathrm{O}_{7}$, as compared to the lack of carbonation for the pure $\mathrm{SrFeO}_{3-\delta}$, we returned to the simulated carbonation equilibria obtained from a previous screening of the Materials Project database. ${ }^{28}$ The relevant simulated carbonation reactions consist of the two possible reactant phases before reduction, along with the possible carbonation of the reduced products (normalised to a reaction with a single molecule of $\mathrm{CO}_{2}$ ):

$$
\begin{gathered}
\mathrm{SrFeO}_{3}+\mathrm{CO}_{2} \longrightarrow \mathrm{SrCO}_{3}+0.5 \mathrm{Fe}_{2} \mathrm{O}_{3}+0.25 \mathrm{O}_{2} \Delta \mathrm{H}=-155.9 \mathrm{kJmol}^{-1} \\
\mathrm{Sr}_{3} \mathrm{Fe}_{2} \mathrm{O}_{7}+\mathrm{CO}_{2} \longrightarrow \mathrm{SrCO}_{3}+2 \mathrm{SrFeO}_{3} \Delta \mathrm{H}=-194.6 \mathrm{kJmol}^{-1}
\end{gathered}
$$




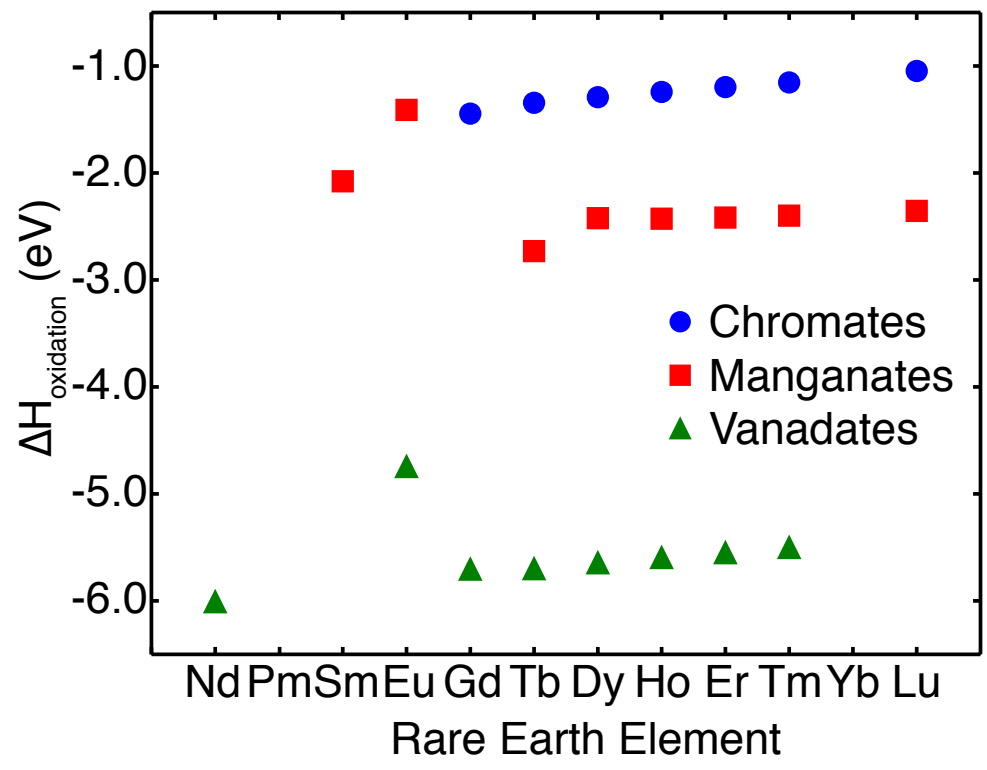

Figure 12: Predicted oxidation energies for rare earth oxides obtained from the screening. The reaction series correspond to the reactions $A B \mathrm{O}_{3} \longrightarrow A B \mathrm{O}_{4}(A=\mathrm{RE}, B=\mathrm{Cr}$ or $\mathrm{V})$ and $\mathrm{ABO}_{3} \longrightarrow \mathrm{A}_{2} \mathrm{~B}_{2} \mathrm{O}_{7}(A=\mathrm{RE}, \mathrm{B}=\mathrm{Mn})$.

$$
\begin{gathered}
0.5 \mathrm{Sr}_{2} \mathrm{Fe}_{2} \mathrm{O}_{5}+\mathrm{CO}_{2} \longrightarrow \mathrm{SrCO}_{3}+0.5 \mathrm{Fe}_{2} \mathrm{O}_{3} \Delta \mathrm{H}=-198.0 \mathrm{kJmol}^{-1} \\
0.33 \mathrm{Sr}_{3} \mathrm{Fe}_{2} \mathrm{O}_{6}+\mathrm{CO}_{2} \longrightarrow \mathrm{SrCO}_{3}+0.33 \mathrm{Fe}_{2} \mathrm{O}_{3} \Delta \mathrm{H}=-203.1 \mathrm{kJmol}^{-1}
\end{gathered}
$$

From these possible equations, we observe that the reduced form of the $\mathrm{Sr}_{3} \mathrm{Fe}_{2} \mathrm{O}_{7}$ impurity, $\mathrm{Sr}_{3} \mathrm{Fe}_{2} \mathrm{O}_{6}$, has the most negative $\Delta H_{\text {carbonation, }}$, and therefore will carbonate preferentially to the other phases present. This comparison is highlighted in the two theoretical carbonation equilibria curves in Figure 13, showing that out of the two reduced species, $\mathrm{Sr}_{3} \mathrm{Fe}_{2} \mathrm{O}_{6}$ will carbonate first over all temperatures.

Furthermore, the carbonation of $\mathrm{SrFeO}_{3}$ involves the release of $\mathrm{O}_{2}$, meaning that it will be disfavoured under high $p_{\mathrm{O}_{2}}$ such as that produced during the reduction reaction. This may well explain its resistance to carbonation observed in our thermogravimetric experiments under $\mathrm{CO}_{2}$. The reduced form, $\mathrm{Sr}_{2} \mathrm{Fe}_{2} \mathrm{O}_{5}$, does not follow the same behaviour, and the absence of carbonation of these phase is most likely due to kinetic effects as seen by Schmidt. ${ }^{59}$ The observed carbonation of the $\mathrm{SrFeO}_{3-\delta}$ phase under repeated, longer cycling, 


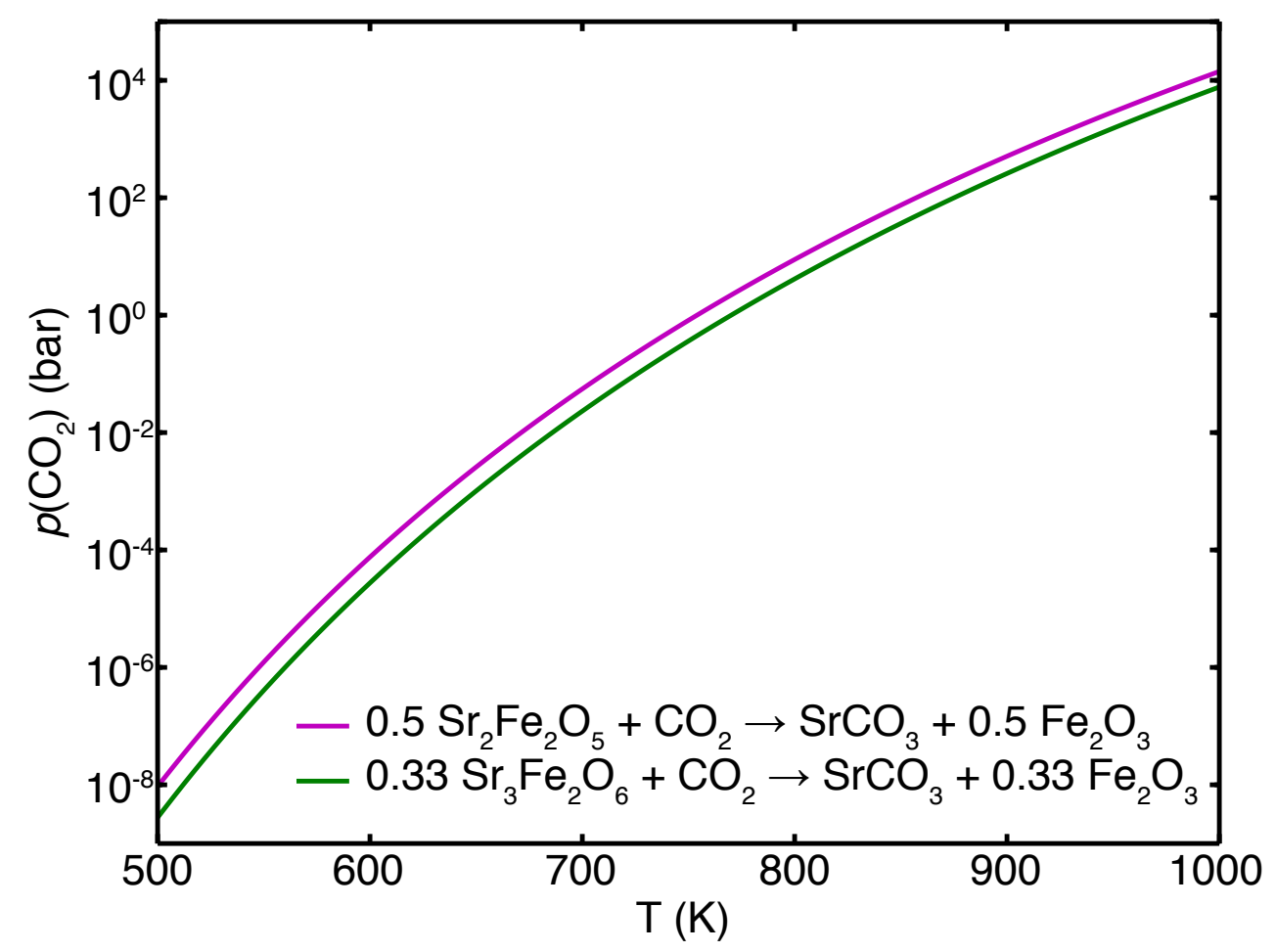

Figure 13: Theoretical carbonation equilibrium curves derived from Materials Project data for $\mathrm{Sr}_{2} \mathrm{Fe}_{2} \mathrm{O}_{5}$ and $\mathrm{Sr}_{3} \mathrm{Fe}_{2} \mathrm{O}_{6}$, the reduction products of $\mathrm{SrFeO}_{3}$ and $\mathrm{Sr}_{3} \mathrm{Fe}_{2} \mathrm{O}_{7}$ respectively. Across all temperatures, $\mathrm{Sr}_{3} \mathrm{Fe}_{2} \mathrm{O}_{6}$ is seen to be more suseptible to carbonation at lower $p_{\mathrm{CO}_{2}}$, suggesting that it may be responsible for the observed carbonation of the mixed phase $\mathrm{SrFeO}_{3-\delta} / \mathrm{Sr}_{3} \mathrm{Fe}_{2} \mathrm{O}_{7}$ sample. 
seen in other experimental studies, possibly arises from the carbonation of $\mathrm{Sr}_{2} \mathrm{Fe}_{2} \mathrm{O}_{5}$ being allowed to reach its thermodynamic equilibrium, or from phase segragation. In either case, these results support our observations that phases resulting from the $\mathrm{Sr}_{3} \mathrm{Fe}_{2} \mathrm{O}_{7}$ impurity lead to the increased carbonation behaviour of this sample.

Finally, a likely direction for further study would be expanding the screening method to include increasingly more complex materials, such as quaternary phases and doped perovskite materials. There are several previous experimental reports of materials such as $\mathrm{La}_{1-\mathrm{x}} \mathrm{Sr}_{\mathrm{x}} \mathrm{FeO}_{3-\delta},{ }^{62} \mathrm{La}_{1-\mathrm{x}} \mathrm{Sr}_{\mathrm{x}} \mathrm{Fe}_{1-\mathrm{y}} \mathrm{Co}_{\mathrm{y}} \mathrm{O}_{3-\delta},{ }^{63}(\mathrm{Ca}, \mathrm{Ba})_{0.9} \mathrm{Sr}_{0.1} \mathrm{Mn}_{0.9} \mathrm{Fe}_{0.1} \mathrm{O}_{3-\delta},{ }^{64} \mathrm{BaYMn}_{2} \mathrm{O}_{5+\delta}{ }^{65}$ and $\mathrm{BaYCo}_{4} \mathrm{O}_{7+\delta}{ }^{66,67}$ amongst others, that have shown promising performance for chemical looping in terms of excellent cycling stability and oxygen capacity, but no systematic experimental study has been done to sample the very large quaternary oxide compositional space. Additionally, as discussed earlier these materials are likely to undergo redox reactions via a series of nonstoichiometric intermediates with different oxygen content, and being able to theoretically determine both the reaction pathway and the energies of the phases along this pathway would enable a more accurate and realistic screening to be done.

As shown in this work, our in silico approach is particularly well suited to such a study, being able to efficiently explore the compositional space in order to discover novel phases for oxygen release. Furthermore, this methodology can be combined with a materials prediction method such as the Structure Predictor app within the Materials Project ${ }^{68}$ to suggest previous unsynthesised phases that could have desirable properties, going beyond currently known materials which current studies are limited to.

\section{Conclusions}

In this study we have shown that a large scale in silico screening methodology utilising existing theoretical databases can be used to find novel materials for chemical looping combustion. Not only is the method efficient at sampling a large chemical and compositional 
space to find optimal candidates based on their predicted thermodynamics, but it also allows for insights into whole classes of compounds found by the screening.

Several promising candidates based on the perovskite to brownmillerite reduction were found by the screening, and were selected for further experimental testing based on their predicted stability under repeated redox cycles. Of the four candidate materials, $\mathrm{SrFeO}_{3-\delta}$ was found to reduce and oxidise at a low enough temperature $(<823 \mathrm{~K})$ to enable a more energy efficient use in carbon capture application. Upon further pressure swing experiments, $\mathrm{SrFeO}_{3-\delta}$ was found to be extremely stable under repeated redox cycles under both $\mathrm{N}_{2}$ and $\mathrm{CO}_{2}$. Furthermore, the stability of $\mathrm{SrFeO}_{3-\delta}$ against carbonation was found to be linked to the sample purity, with other strontium ferrite phases present in multiphase samples being found to be responsible for carbonation of the sample.

These results illustrate the growing importance that data mining techniques can have in materials discovery across a variety of functional applications. With the proliferation of both theoretical and experimental data in open accessible databases such an approach can be routinely included to both efficiently identify novel materials with desirable properties and to assist in examining the chemical trends underlying the performance of optimal materials, both already known and yet to be discovered.

\section{Acknowledgements}

All authors acknowledge funding from EPSRC Grant No. EP/K030132/1. M.T. Dunstan acknowledges funding from the Cambridge Commonwealth Trusts, Trinity College, Cambridge and is a recipient of a STFC Futures Early Career Award. The authors gratefully acknowledge Anubhav Jain (Computational Research Division, Lawrence Berkeley National Laboratory), Shyue Ping Ong (Department of NanoEngineering, University of California San Diego) and Kristin Persson (Department of Materials Science and Engineering, University of California Berkeley) for their advice and assistance in accessing the Materials Project, which 
itself is supported through the U.S. Department of Energy, Office of Basic Energy Sciences, Materials Project Center Grant No. EDCBEE. The authors also gratefully acknowledge Ewa Marek for her help with some of the thermogravimetric studies.

\section{Data}

All supporting data for this work can be found on https://www.repository.cam.ac.uk.

\section{References}

(1) Pacala, S. Science 2004, 305, 968-972.

(2) Fan, L.-S.; Zeng, L.; Wang, W.; Luo, S. Energy Environ. Sci. 2012, 5, 7254-7280.

(3) Lewis, W.; Gilliland, E.; Sweeney, M. Chem. Eng. Prog. 1951, 47, 251-256.

(4) Ishida, M.; Zheng, D.; Akehata, T. Energy 1987, 12, 147-154.

(5) Richter, H.; Knoche, K. ACS Symp. Ser. 1983, 235, : 71-85.

(6) Lyngfelt, A.; Leckner, B.; Mattisson, T. Chem. Eng. Sci. 2001, 56, 3101-3113.

(7) Ishida, M.; Jin, H. Energy 1994, 19, 415-422.

(8) Rochelle, G. Science 2009, 325, 1652-1654.

(9) Adanez, J.; Abad, A.; Garcia-Labiano, F.; Gayan, P.; Luis, F. Prog. Energy Combust. Sci. 2012, 38, 215-282.

(10) Ohlemüller, P.; Busch, J.-P.; Reitz, M.; Ströhle, J.; Epple, B. J. Energy Resour. Tech. 2016, 138, 042203-042203.

(11) Cho, P.; Mattisson, T.; Lyngfelt, A. Fuel 2004, 83, 1215 - 1225.

(12) Abad, A.; Adánez, J.; García-Labiano, F.; de Diego, L. F.; Gayán, P.; Celaya, J. Chem. Eng. Sci. 2007, 62, 533-549.

(13) Galinsky, N.; Sendi, M.; Bowers, L.; Li, F. Appl. Energy 2016, 174, 80-87.

(14) Leion, H.; Larring, Y.; Bakken, E.; Bredesen, R.; Mattisson, T.; Lyngfelt, A. Energy 83 Fuels 2009, 23, 5276-5283.

(15) Donat, F.; Hu, W.; Scott, S. A.; Dennis, J. S. Ind. Eng. Chem. Res. 2015, 54, 67136723.

(16) Imtiaz, Q.; Broda, M.; Müller, C. R. Appl. Energy 2014, 119, 557-565. 
(17) Moldenhauer, P.; Rydén, M.; Lyngfelt, A. Fuel 2012, 93, 351-363.

(18) Clayton, C. K.; Whitty, K. J. Appl. Energy 2014, 116, 416-423.

(19) Mattisson, T.; Lyngfelt, A.; Leion, H. Int. J. Greenhouse Gas Control 2009, 3, 11-19.

(20) Brown, T. A.; Dennis, J. S.; Scott, S. A.; Davidson, J. F.; Hayhurst, A. N. Energy $\&$ Fuels 2010, 24, 3034-3048.

(21) Moghtaderi, B. Energy \& Fuels 2010, 24, 190-198.

(22) Shah, K.; Moghtaderi, B.; Zanganeh, J.; Wall, T. Fuel 2013, 107, 356-370.

(23) Davies, R. H.; Dinsdale, A. T.; Gisby, J. A.; Robinson, J. A. J.; Martin, S. M. Calphad 2002, 26, 229-271.

(24) Otto, E. M. 1965, 112, 367-370.

(25) Jensen, W. B. J. Chem. Educ. 2009, 86, 1266.

(26) Jain, A.; Ong, S. P.; Hautier, G.; Chen, W.; Richards, W. D.; Dacek, S.; Cholia, S.; Gunter, D.; Skinner, D.; Ceder, G.; Persson, K. A. APL Mater. 2013, 1, 011002.

(27) Saal, J. E.; Kirklin, S.; Aykol, M.; Meredig, B.; Wolverton, C. JOM 2013, 65, 15011509.

(28) Dunstan, M. T.; Jain, A.; Liu, W.; Ong, S. P.; Liu, T.; Lee, J.; Persson, K. A.; Scott, S. A.; Dennis, J. S.; Grey, C. P. Energy Environ. Sci. 2016, 9, 1346-1360.

(29) Lin, L.-C.; Berger, A. H.; Martin, R. L.; Kim, J.; Swisher, J. A.; Jariwala, K.; Rycroft, C. H.; Bhown, A. S.; Deem, M. W.; Haranczyk, M.; Smit, B. Nat. Mater. 2012, 11, 633-641.

(30) Huck, J. M.; Lin, L.-C.; Berger, A. H.; Shahrak, M. N.; Martin, R. L.; Bhown, A. S.; Haranczyk, M.; Reuter, K.; Smit, B. Energy Environ. Sci. 2014, 7, 4132-4146.

(31) Kresse, G. Phys. Rev. B 1996, 54, 11169-11186.

(32) Kresse, G.; Furthmüller, J. Comp. Mater. Sci. 1996, 6, 15-50.

(33) Ong, S. P.; Cholia, S.; Jain, A.; Brafman, M.; Gunter, D.; Ceder, G.; Persson, K. A. Comp. Mater. Sci. 2015, 97, 209-215.

(34) Ong, S. P.; Richards, W. D.; Jain, A.; Hautier, G.; Kocher, M.; Cholia, S.; Gunter, D.; Chevrier, V. L.; Persson, K. A.; Ceder, G. Comp. Mater. Sci. 2013, 68, 314-319.

(35) Ping Ong, S.; Wang, L.; Kang, B.; Ceder, G. Chem. Mater. 2008, 20, 1798-1807.

(36) Jain, A.; Hautier, G.; Ong, S. P.; Moore, C. J.; Fischer, C. C.; Persson, K. A.; Ceder, G. Phys. Rev. B 2011, 84, 045115. 
(37) Ong, S. P.; Jain, A.; Hautier, G.; Kang, B.; Ceder, G. Electrochem. Comm. 2010, 12, 427-430.

(38) Wang, L.; Maxisch, T.; Ceder, G. Phys. Rev. B 2006, 73, 195107.

(39) Pechini, M. P. US Patent no. 3.330.697; 1967.

(40) Barin, I. Thermochemical Data of Pure Substances; Wiley-VCH Verlag GmbH, 2008.

(41) Chase, M. W. J. NIST-JANAF Thermochemical Tables, 4th Edition; American Institute of Physics: New York, 1998.

(42) Kazakov, S. M.; Chaillout, C.; Bordet, P.; Capponi, J. J.; Nunez-Regueiro, M.; Rysak, A.; Tholence, J. L.; Radaelli, P. G.; Putilin, S. N.; Antipov, E. V. Nature 1997, 390, 148-150.

(43) Syono, Y.; iti Akimoto, S.; Kohn, K. Journal of the Physical Society of Japan 1969, 26, 993-999.

(44) Ong, S. P.; Jain, A.; Hautier, G.; Kang, B.; Ceder, G. Electrochemistry Communications 2010, 12, $427-430$.

(45) Parras, M.; Gonzalez-Calbet, J.; Vallet-Regi, M.; Grenier, J. Solid State Ionics 1993, 63, 714-718.

(46) Grenier, J.-C.; Wattiaux, A.; Pouchard, M.; Hagenmuller, P.; Parras, M.; Vallet, M.; Calbet, J.; Alario-Franco, M. J. Solid State Chem. 1989, 80, 6-11.

(47) Hodges, J.; Short, S.; Jorgensen, J.; Xiong, X.; Dabrowski, B.; Mini, S.; Kimball, C. J. Solid State Chem. 2000, 151, 190 - 209.

(48) Takeda, Y.; Kanno, K.; Takada, T.; Yamamoto, O.; Takano, M.; Nakayama, N.; Bando, Y. J. Solid State Chem. 1986, 63, 237-249.

(49) Schmidt, M. J. Phys. Chem. Solids 2000, 61, 1363-1365.

(50) Holt, A.; Norby, T.; Glenne, R. Ionics 1999, 5, 434-443.

(51) Mizusaki, J.; Okayasu, M.; Yamauchi, S.; Fueki, K. J. Solid State Chem. 1992, 99, 166-172.

(52) Vashuk, V.; Kokhanovskii, L.; Yushkevich, I. Inorg. Mater. 2000, 36, 79-83.

(53) MacChesney, J. B.; Sherwood, R. C.; Potter, J. F. J. Chem. Phys. 1965, 43, 1907-1913.

(54) Bucher, E.; Egger, A.; Caraman, G.; Sitte, W. J. Electrochem. Soc. 2008, 155, B1218B1224.

(55) Yan, A.; Cheng, M.; Dong, Y.; Yang, W.; Maragou, V.; Song, S.; Tsiakaras, P. Appl. Cat., B 2006, 66, 64-71. 
(56) Nomura, K.; Ujihira, Y.; Hayakawa, T.; Takehira, K. Appl. Cat., A 1996, 137, 25-36.

(57) Kharton, V.; Yaremchenko, A.; Kovalevsky, A.; Viskup, A.; Naumovich, E.; Kerko, P. J. Membrane Sci. 1999, 163, 307-317.

(58) Shen, Q.; Zheng, Y.; Luo, C.; Zheng, C. Bull. Korean Chem. Soc. 2014, 35, 1613.

(59) Schmidt, M. Mater. Res. Bull. 2002, 37, $2093-2105$.

(60) Petit, L.; Svane, A.; Szotek, Z.; Temmerman, W. M. Phys. Rev. B 2005, 72, 205118.

(61) Petit, L.; Szotek, Z.; Lüders, M.; Svane, A. J. Phys. Condens. Matter 2016, 28, 223001.

(62) Taylor, D. D.; Schreiber, N. J.; Levitas, B. D.; Xu, W.; Whitfield, P. S.; Rodriguez, E. E. Chem. Mater. 2016, 28, 3951-3960.

(63) Ryden, M.; Lyngfelt, A.; Mattisson, T.; Chen, D.; Holmen, A.; Bjørgum, E. Int. J. Greenhouse Gas Control 2008, 2, 21 - 36.

(64) Hamedi Rad, M. Processing and Evaluation of Next Generation Oxygen Carrier Materials for Chemical Looping Combustion. Ph.D. thesis, University of Toledo, 2015.

(65) Motohashi, T.; Takahashi, T.; Kimura, M.; Masubuchi, Y.; Kikkawa, S.; Kubota, Y.; Kobayashi, Y.; Kageyama, H.; Takata, M.; Kitagawa, S.; Matsuda, R. J. Phys. Chem. C 2015, 119, 2356-2363.

(66) Hao, H.; Cui, J.; Chen, C.; Pan, L.; Hu, J.; Hu, X. Solid State Ionics 2006, 177,631 637.

(67) Karppinen, M.; Yamauchi, H.; Otani, S.; Fujita, T.; Motohashi, T.; Huang, Y.-H.; Valkeapää, M.; Fjellvåg, H. Chem. Mater. 2006, 18, 490-494.

(68) Hautier, G.; Fischer, C.; Ehrlacher, V.; Jain, A.; Ceder, G. Inorg. Chem. 2011, 50, 656-663. 